Revista Brasileira de Cartografia

ISSN 1808-0936 | https://doi.org/10.14393/revbrascartogr

Sociedade Brasileira de Cartografia, Geodésia, Fotogrametria e Sensoriamento Remoto

\title{
50 anos de sinergia entre Geodésia Espacial e Meteorologia: do erro no posicionamento GNSS a aplicações de previsão de precipitação de curtíssimo prazo
}

\section{0 years of synergy between Space Geodesy and Meteorology: from a GNSS positioning error to precipitation nowcasting applications}

Tayná Aparecida Ferreira Gouveia ${ }^{1}$, João Francisco Galera Monico ${ }^{2}$, Daniele Barroca Marra Alves ${ }^{3}$, Luiz Fernando Sapucci $^{4}$ e Felipe Geremia-Nievinski ${ }^{5}$

\author{
1 Universidade Estadual Paulista (UNESP), Departamento de Engenharia Cartográfica, Presidente Prudente - SP, Brasil. E-mail. \\ tayna.gouveia@unesp.br \\ ORCID: https://orcid.org/0000-0003-1140-752X \\ 2 Universidade Estadual Paulista (UNESP), Departamento de Engenharia Cartográfica, Presidente Prudente - SP, Brasil. E-mail. \\ galera.monico@unesp.br \\ ORCID: https://orcid.org/ 0000-0003-4101-9261 \\ 3 Universidade Estadual Paulista (UNESP), Departamento de Engenharia Cartográfica, Presidente Prudente - SP, Brasil. E-mail. \\ daniele.barroca@unesp.br \\ ORCID: https://orcid.org/ 0000-0002-9033-8499 \\ 4 Instituto Nacional de Pesquisas Espaciais (INPE), Centro de Previsão de Tempo e Estudos Climáticos (CPTEC), Divisão de \\ Desenvolvimento e Modelagem, Cachoeira Paulista - SP, Brasil. E-mail. luiz.sapucci@inpe.br \\ ORCID: https://orcid.org/ 0000-0001-8420-8033 \\ 5 Universidade Federal do Rio Grande do Sul (UFRGS), Departamento de Geodésia, Porto Alegre - RS, Brasil. E-mail. \\ felipe.nievinski@ufrgs.br \\ ORCID: https://orcid.org/ 0000-0002-3325-1987
}

Recebido: 08.2020 | Aceito: 11.2020

\begin{abstract}
Resumo: A atmosfera neutra (ou troposfera) causa refração nos sinais de radiofrequência, que resulta em erros nas medidas do Global Navigation Satellite Systems (GNSS) empregadas no posicionamento geodésico. Já para a Meteorologia esse efeito pode representar medidas importantes da concentração dos constituintes atmosféricos, principalmente em regiões onde não se pode realizar sondagem atmosférica convencional, por meio de radiossondas acopladas a balões. Duas técnicas GNSS podem ser empregadas para isso. A primeira utiliza receptores em estações terrestres que fornecem estimativas do conteúdo integrado verticalmente de umidade na atmosfera neutra (Precipitable Water Vapor - PWV). A segunda, com receptores localizados em plataformas espaciais, com os quais obtém perfis atmosféricos de pressão, temperatura e umidade, na técnica conhecida como Rádio-ocultação GNSS. Essas medidas têm um potencial significativo para aplicações em previsões de curtíssimo prazo (30 minutos) de eventos extremos de precipitação (>35 mm). O objetivo principal deste artigo é realizar uma revisão do estado da arte da sinergia entre a Geodésia e a Meteorologia na modelagem da atmosfera neutra (neutrosfera), seu efeito no posicionamento GNSS e na estimativa dos constituintes atmosféricos e suas aplicações. Além disso, apresenta os aprimoramentos e novos desafios desenvolvidos na modelagem do atraso para o posicionamento de alta acurácia.
\end{abstract}

Palavras-chave: Atmosfera Neutra. GNSS e Meteorologia. Atraso da atmosfera neutra. PWV-GNSS.

\begin{abstract}
The neutral atmosphere (or troposphere) causes refraction in radio frequency signals, which results in errors in Global Navigation Satellite Systems (GNSS) measurements. In meteorology, this effect can represent important measurements of the concentration of atmospheric constituents, especially in regions where conventional high-altitude atmospheric sounding (radiosondes) cannot be performed. There are two GNSS techniques used for this. In the first one, GNSS receivers are located on terrestrial stations that provide estimates of the vertically integrated moisture content (Precipitable Water Vapor - PWV). In the second case, receivers are in space platforms, which obtains profiles of atmospheric pressure, temperature and humidity, known as GNSS radio occultation. These measurements have significant potential for nowcasting applications (30 minutes in advance) of extreme precipitation events $(>35 \mathrm{~mm}$ ). This paper presents a review of the state of the art in the synergy between Geodesy and Meteorology for modeling the neutral atmosphere (neutrosphere), its effect on GNSS positioning and in the estimation of atmospheric constituents, and their applications. Furthermore, it offers the improvements and new challenges developed in modeling the delay for high accuracy positioning.
\end{abstract}

Keywords: Neutral atmosphere. GNSS and Meteorology. Neutral atmosphere delay. PWV-GNSS. 


\section{INTRODUÇÃO}

Em diferentes situações do cotidiano, conhecer a localização em que se encontra, ou a que se deseja chegar, é de fundamental importância para diversas aplicações, as quais vão das mais simples às mais complexas, tais como: locomoção, planejamento de viagens, agricultura de precisão (plantação e/ou colheita), construções civis de infraestrutura (pontes, estradas, barragens), pouso e decolagem de aeronaves, plataformas de petróleo, veículos autônomos etc. Nesse processo, a Geodésia tem um papel fundamental por meio do uso de satélites, em especial dos Sistemas Globais de Navegação por Satélite (em inglês, Global Navigation Satellite Systems - GNSS), tecnologia que revolucionou o posicionamento e a navegação. Diferentes fontes de erro afetam as medidas GNSS, desde sua transmissão (no satélite) até sua recepção (na antena), para o qual muita pesquisa foi, e ainda é, necessária. Detalhes das fontes de erro podem ser encontrados em Monico (2008) e Teunissen e Montenbruck (2017).

Uma dessas fontes está associada com a porção eletricamente neutra da atmosfera, chamada de atmosfera neutra (ou neutrosfera), que vai da superfície terrestre até aproximadamente $50 \mathrm{~km}$. Os constituintes dessa camada, como vapor d'água e outros gases, apresentam variação e causam refração das ondas de rádio nas frequências utilizadas pelo GNSS. Isso resulta em um atraso de propagação do sinal, com relação ao vácuo, da ordem de 2,3 m a 2,6 m para satélites no zênite, até dez vezes mais para satélites próximos ao horizonte (com elevação de 5) (DAVIS et al., 1985; SAPUCCI, 2001; MONICO, 2008; NIEVINSKI, 2009; TEUNISSEN; MONTENBRUCK, 2017).

$\mathrm{Na}$ Geodésia, a atmosfera neutra representa uma fonte de erro ao posicionamento, e seu respectivo atraso pode ser tratado de duas maneiras. A primeira se dá a partir da modelagem ou cálculo do atraso considerando os valores dos gases constituintes da atmosfera neutra (pressão, temperatura e vapor d'água) advindos de fontes da Meteorologia (SAPUCCI, 2001; SEEBER, 2003). A segunda é dependente das medidas GNSS, onde o atraso residual é estimado como parâmetro desconhecido no processamento dessas medidas (MONICO, 2008; TEUNISSEN; MONTENBRUCK, 2017).

A partir das medidas dos constituintes atmosféricos é possível calcular o índice de refração e a refratividade do ar, e com isso o atraso de propagação. Podem ser aplicados modelos do atraso empíricos, baseados em climatologias. Há também outras metodologias, que consideram a integral da refratividade que sofre a influência de todos os níveis da atmosfera (HOPFIELD, 1971; SAASTAMOINEN, 1972; ASKNE; NORDIUS, 1987; DAVIS et al., 1985). A integral do atraso zenital é mais simples, pois o trajeto do sinal é restrito à direção vertical.

Já a determinação do atraso na direção inclinada, de acordo com o ângulo de elevação e azimute específico, é realizada através do traçado de raios (ou ray tracing) (HOBIGER et al., 2008a; HOBIGER et al., 2008b; NIEVINSKI, 2009; NIEVINSKI; SANTOS, 2010). Na prática, as funções de mapeamento são uma forma conveniente de disponibilizar para o usuário final a razão entre o atraso zenital e o atraso inclinado (MARINI, 1972; NIELL, 1996; BOEHM et al., 2004; BOEHM et al., 2006a; BOEHM et al., 2006b e 2007; URQUHART, 2010; LANDSKRON et al., 2018).

A qualidade dos dados e modelos atmosféricos têm impacto direto na acurácia do atraso de propagação calculado. Diante disso, a modelagem do atraso da atmosfera neutra representa uma área de pesquisa, a qual se propõe investigar a melhor técnica e fonte de dados dos constituintes atmosféricos. A melhor modelagem do atraso, assim como melhor precisão e resolução espaço-temporal, têm sido investigadas e tem apresentado resultados promissores.

Nas últimas décadas, os GNSS têm-se apresentado, para a Meteorologia, como um sistema de observação atmosférico acurado e uma fonte adicional de informações da atmosfera. Os efeitos da refração atmosférica nos sinais GNSS, que representam erros nas aplicações de posicionamento, são fontes de informação que podem ser convertidos em medidas úteis na Meteorologia (GUTMAN et al., 2003; SAPUCCI et al., 2010). Quando os receptores GNSS estão em bases terrestres, como as redes de monitoramento contínuos, obtém-se o vapor d'água integrado (Precipitable Water Vapor - PWV) com boa qualidade e alta resolução temporal (SAPUCCI et al., 2007a; SAPUCCI et al., 2007b). Na técnica denominada Rádio Ocultação GNSS (RO-GNSS), os receptores GNSS são embarcados em bases espaciais, e com eles pode-se obter perfis da concentração os constituintes atmosféricos com alta resolução vertical (SAPUCCI et al., 2014b; 
BONAFONI et al., 2020). Os perfis de RO-GNSS têm apresentado um forte impacto na qualidade dos produtos de PNT dentro do processo de assimilação de dados, sendo o segundo sistema de observação em ordem de importância (BANOS et al, 2019). Como a abordagem na obtenção das medidas de receptores em bases terrestres é bastante diferente dos receptores em bases espaciais, apenas a primeira será detalhada nesse artigo, enquanto que a segunda trabalhos já publicados serão referenciados, a fim de simplificação. A sinergia entre a Geodésia e a Meteorologia culmina na área de pesquisa denominada GNSS-Meteorologia (SAPUCCI et al., 2007a; SAPUCCI et al., 2007b; SMITH et al, 2007; YAN et al., 2009; SAPUCCI et al, 2010; GUEROVA et al., 2016). A Meteorologia fornece previsão da concentração dos constituintes atmosféricos para o cálculo do atraso para posicionamento acurado e em tempo real. A Geodésia, por sua vez, pela tecnologia GNSS, fornece medidas da concentração dos constituintes atmosféricos como fonte adicional de observação. No processo de assimilação dos dados essa sinergia se concretiza, pois observações GNSS em bases terrestres (PWV) e em bases espaciais (perfis atmosféricos da RO-GNSS) são incorporados na PNT, os quais geram produtos que são utilizados na modelagem do atraso em aplicações geodésicas. Isso representa um ciclo que se retroalimenta, em que se evidencia a importância da evolução das pesquisas em ambas as áreas do conhecimento.

No mundo, há mais de 50 anos são investigados os efeitos da atmosfera neutra em aplicações geodésicas e o uso complementar da assimilação de dados para a PNT. O estado da arte na modelagem do atraso atmosférico muitas vezes não se apresenta adequado para o Brasil. As suas dimensões continentais e características climáticas muito distintas para um mesmo dia nas diferentes regiões, com a forte influência da floresta amazônica e dos oceanos na circulação atmosférica, se apresenta como um desafiador cenário de pesquisas. Por isso, no Brasil, há quase duas décadas, é investigado o impacto da atmosfera neutra no posicionamento GNSS considerando as particularidades do território brasileiro. Modelos de PNT nacionais vêm apresentando resultados promissores no posicionamento GNSS em relação aos modelos globais, devido às resoluções espaço-temporal neles empregados. Logo, ter uma descrição da atmosfera neutra de qualidade, como a disponibilizada pelo Centro de Previsão de Tempo e Estudos Climáticos (CPTEC) do Instituto Nacional de Pesquisas Espaciais (INPE), resulta em melhor acurácia no posicionamento GNSS (ALVES et al., 2015). Muitos pesquisadores de diversas instituições nacionais associados ao Grupo de Estudos em Geodésia Espacial (GEGE) da Universidade Estadual Paulista (Unesp) têm atuado sobre o eixo de investigação da modelagem do atraso de propagação GNSS devido à atmosfera neutra e suas aplicações em previsões de curtíssimo prazo (nowcasting) de eventos atmosféricos extremos de precipitação. Um estudo recente propõe o uso de receptores GNSS para prever (com antecedência de 30 minutos) eventos extremos de precipitação (>35mm) (SAPUCCI et al., 2019) e há projetos visando explorar dados do COSMIC-2 (constelação de satélites equatoriais dedicados para RO-GNSS) para prever eventos extremos de precipitação (BANOS et al., 2018). Um desenvolvimento em paralelo vem sendo a tomografia do vapor d'água (BRENOT et al., 2020), com potencial de melhor detalhar a distribuição temporal e espacial dessa variável (MOELLER et al., 2020). É consenso que previsão de tempo em condições atmosféricas extremas (severas) é desafiadora e encontra-se na fronteira do conhecimento humano, no qual a sinergia em diferentes áreas do conhecimento é um dos ingredientes mais importantes para se obter o sucesso. Frente ao exposto, esse artigo tem por objetivo realizar uma revisão teórica e histórica da sinergia entre a Geodésia e a Meteorologia na modelagem da atmosfera neutra, seu efeito no posicionamento GNSS e na estimativa da concentração dos constituintes atmosféricos e suas aplicações.

A comunidade científica, usualmente, denomina "troposféricos" os efeitos que o sinal sofre ao ultrapassar essa camada, ou efeito de propagação troposférica (MONICO, 2008; TEUNISSEN; MONTENBRUCK, 2017). Mas está totalmente adequada a simplificação da atmosfera neutra em troposfera? Cerca de $25 \%$ do atraso de propagação se encontra acima da troposfera $(15$ a $18 \mathrm{~km})$, ou seja, o termo atmosfera neutra se torna mais adequado por expressar a real dimensão e característica dessa região da atmosfera para fins de propagação (MENDES, 1999; TEUNISSEN; MONTENBRUCK, 2017). Visando discutir essa questão, antes de tratar do erro que a atmosfera neutra causa no sinal GNSS, na seção 2 é tratado como se caracteriza essa camada em termos conceituais e de nomenclatura. Para atingir o objetivo proposto, esse artigo apresenta um compêndio das diferentes fontes de dados e modelos na seção 3 (seção 3.3), suas resoluções espaciais e temporais distintas, suas limitações, vantagens e desvantagens. Serão apresentados os métodos para medição 
da atmosfera, assim como para o cálculo do atraso (seção 3.4). Serão discutidos aprimoramentos e novos desafios desenvolvidos na modelagem do atraso para o posicionamento de alta acurácia (seção 3.5), como também sobre os resultados e produtos disponíveis (seção 3.6).

\section{ATMOSFERA NEUTRA: CONCEITOS E NOMENCLATURAS}

Os sinais transmitidos pelos satélites GNSS são ondas de rádio que se propagam através da atmosfera terrestre, a qual é dinâmica, composta por camadas de diferentes características e com estados variáveis. Esses sinais sofrem variações na sua velocidade de propagação (direção e magnitude ou rapidez), polarização e potência.

A atmosfera terrestre é composta por uma mistura de gases com diferentes proporções. A sua extensão vertical é definida devido a sua massa total, a qual decai exponencialmente, sendo que $90 \%$ se encontra nos primeiros $20 \mathrm{~km}$ e $99 \%$ até $50 \mathrm{~km}$; acima de $100 \mathrm{~km}$, existe apenas cerca de um milionésimo da massa total atmosférica. Sua estrutura vertical é devida à sua composição (propriedades físicas e químicas). Essas variações na atmosfera a caracterizam como um conjunto de camadas, esféricas e concêntricas à Terra, não homogêneas, com características próprias (VIANELLO; ALVES, 2000).

A quantidade de camadas, suas divisões e suas denominações dependem da área de investigação. Do ponto de vista da concentração dos gases, a divisão se dá de acordo com o gradiente de temperatura, composta por quatro camadas: termosfera, mesosfera, estratosfera e troposfera com três superfícies limítrofes intermediárias: tropopausa, estratopausa e mesopausa (WALLACE; HOBBS, 2005). Em contraste, para fins de propagação de ondas de radiofrequência (aplicações geodésicas), a atmosfera é dividida essencialmente em duas camadas, a parte eletricamente neutra e a parte ionizada, cada uma com características bem diferentes. A camada ionizada, composta pela termosfera até a mesosfera, é chamada de ionosfera e tem espessura de $50 \mathrm{~km}$ a $1000 \mathrm{~km}$. A camada eletricamente neutra, que a partir da superfície terrestre, é composta pela troposfera, tropopausa e estratosfera, com espessura de $50 \mathrm{~km}$, onde inicia a Ionosfera, ou ainda, podendo chegar até a 100 km, início do vácuo (MENDES, 1999; NIEVINSKI, 2009). As ondas eletromagnéticas transmitidas pelos satélites GNSS passam primeiro pela ionosfera, antes de entrar na atmosfera neutra. Em ambos os meios os sinais eletromagnéticos são atrasados e refratados (TEUNISSEN; MONTENBRUCK, 2017).

Na figura 1 são apresentadas as camadas da atmosfera. Na Figura 1a as camadas são devidas devido a presença de íons ou não, sobrepostas às camadas divididas em função da variação de temperatura. Já a Figura $1 b$ apresenta a variação da temperatura em relação a altitude, onde nas inflexões definem-se as camadas nas concentrações dos gases. É preciso enfatizar que a correspondência entre as duas formas de estratificação não é exata, pois a ionosfera não inclui toda a mesosfera e a atmosfera neutra pode avançar para além da estratopausa.

A ionosfera é composta por gases rarefeitos que combinados com as altas temperaturas caracterizam o estado da matéria denominado de plasma, onde há grande concentração de energia. Devido à ação da radiação solar nesta camada, há considerável quantidade de átomos e moléculas ionizadas, assim como os elétrons livres (VIANELLO; ALVES, 2000). Tal composição causa diferentes efeitos nos sinais GNSS (como refração e até perda do sinal). Ao passar por essa camada, ondas de radiofrequência são afetadas de forma dependente da frequência eletromagnética, visto que o índice de refração é uma função da frequência. A magnitude desse erro é proporcional à densidade de elétrons livres presentes na ionosfera, o que apresenta variação temporal e espacial. Os efeitos ionosféricos de maior magnitude podem ser eliminados pelo processamento de dupla frequência das observáveis, a partir da combinação livre de ionosfera (ion-free) (CAMARGO, 1999). Os efeitos secundários, embora representem menor magnitude, também precisam ser minimizados para aplicações que requeiram alta precisão (IERS, 2010; MARQUES et al., 2011; MARQUES et al., 2014).

Depois da ionosfera, a atmosfera eletricamente neutra apresenta os maiores erros no posicionamento GNSS. Para fins de propagação de radiofrequência, a camada neutra também é denominada de troposfera. A forte influência da troposfera se dá pela sua composição e massa. A troposfera é a camada em contato com a superfície da Terra e atinge altitude aproximada de $15 \mathrm{~km}$ a $18 \mathrm{~km}$. Ela é composta por gases secos (N2, O2, $\mathrm{CO} 2$ ) e por vapor d'água. Os gases secos são bastante homogêneos e constantes - exceto pelo CO2, que tem variação entre dia e noite próximo à superfície e variam de acordo com a pressão e temperatura. Apesar da 
baixa concentração do vapor d'água, cerca de $0,25 \%$, em comparação com os outros elementos (N2 com 78\%, e o O2 com 20\%), esta é a componente que apresenta maior variação, espacial e temporal. Sua concentração não é uniforme e ocorre nos quilômetros mais baixos da atmosfera (abaixo de $10 \mathrm{~km}$, com maior concentração nos $4 \mathrm{~km}$ iniciais), e em regiões tropicais quentes e úmidas, devido ao processo de evaporação da água, dependente da variação da altitude (WALLACE; HOBBS, 2005; VIANELLO; ALVES, 2000; TEUNISSEN; MONTENBRUCK, 2017). A variação da temperatura, da umidade e da pressão, em relação a altitude (VIANELLO; ALVES, 2000), é exemplificada na figura 2. Pode-se notar que há uma diminuição expressiva da umidade com o aumento da altitude. Assim, caracteriza-se a parte úmida da atmosfera neutra nos primeiros $10 \mathrm{~km}$, e a seca de 10 a $15 \mathrm{~km}$, até 50-60 km (HOFMANN-WELLENHOF, 2008).

Figura 1 - Camadas da atmosfera terrestre em relação (a) propagação de ondas de radiofrequência e (b) na concentração dos gases em função da variação de temperatura em relação a altitude.

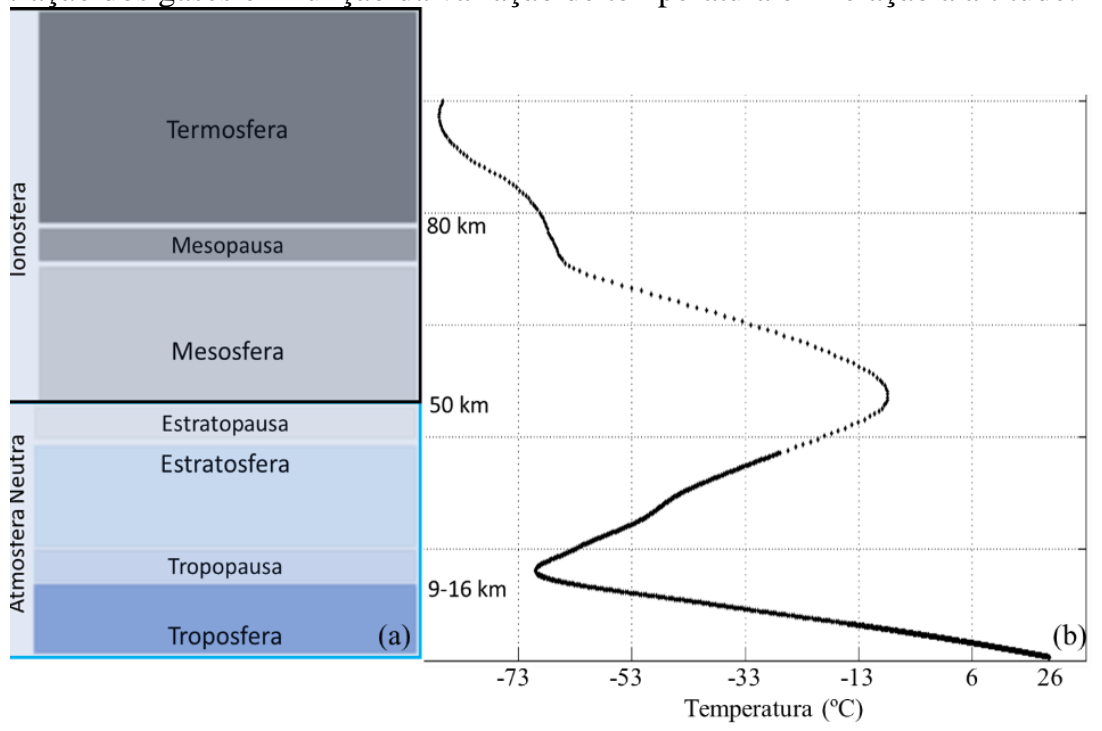

Fonte: Os autores (2020).

Figura 2 - Variação da pressão $(P)$, temperatura $(T)$ e umidade (Umrl) em relação da altitude para a estação de Manaus em 01 de janeiro de 2017.

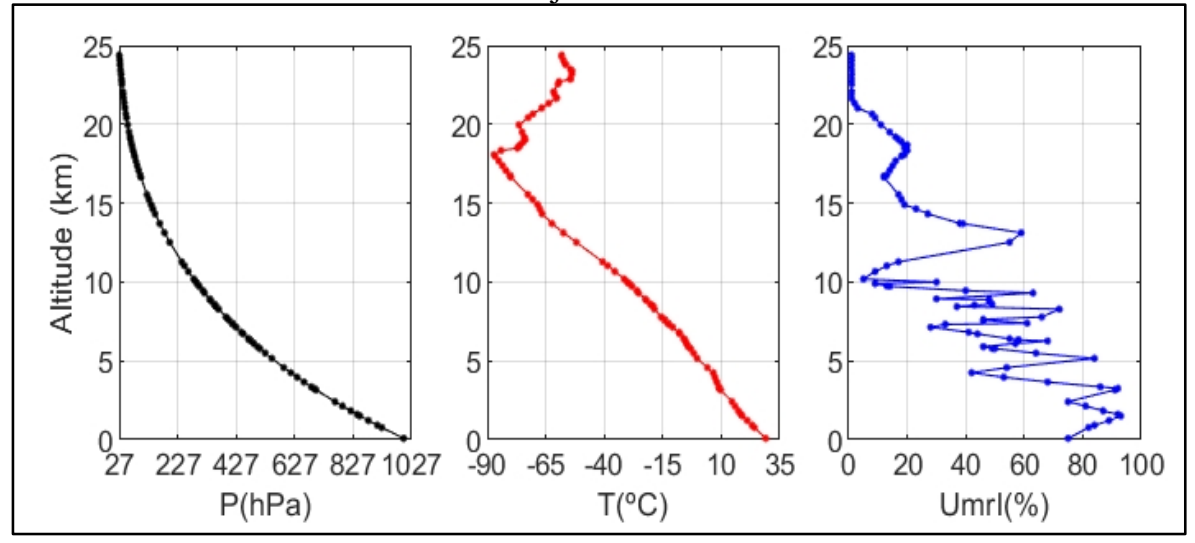

Fonte: Os autores (2020).

A atmosfera neutra não é apenas a troposfera, embora seja utilizada essa denominação devido à preponderância da mesma na composição total (MENDES, 1999). A simplificação da atmosfera neutra em troposfera não é adequada, uma vez que cerca de $25 \%$ do atraso de propagação seria desconsiderado. Isso implica desconsiderar os gases que estão localizados acima da troposfera, em particular gases na estratosfera (TEUNISSEN; MONTENBRUCK, 2017).

Como se pode notar, a camada neutra não é apenas a troposfera. Considerando que a camada oposta a essa é denominada Ionosfera, devido a presença de íons, a camada livre de íons ou eletricamente neutra, estaria mais adequadamente denominada por Neutrosfera, como proposto por Chapman (1950). Porém, essa 
nomenclatura, embora mais adequada, não foi referenciada pela maioria dos autores da Geodésia GNSS, nem pelas obras mais específicas, como Boehm e Schuh (2013) ou Elgered e Wickert (2017). Essa nomenclatura é estendida para a refração e o atraso (e suas componentes) da atmosfera neutra ou da neutrosfera (ou neutrosférica(o)).

Nesse sentido, cabem algumas questões a serem discutidas: Como obter informações dos constituintes da atmosfera neutra? Como calcular o atraso? Quais acurácias e resolução espaço-temporal são necessárias? Considerando o cenário climatológico brasileiro, quais são as melhores modelagens do atraso? As próximas seções pretendem discutir e apresentar as investigações e possíveis respostas.

\section{MODELAGEM DO ATRASO DA ATMOSFERA NEUTRA: CONTRIBUIÇÃO DA METEOROLOGIA PARA A GEODÉSIA}

O atraso de propagação da onda eletromagnética devido à atmosfera neutra não pode ser medido diretamente. Por essa razão, se faz necessário aplicar uma modelagem, que é uma estrutura simplificada da realidade, mais geral. Nesta modelagem, são consideradas as leis da refração, das ondas eletromagnéticas e da variação do índice de refração, como também o formato da Terra com representação esférica, além de hipóteses baseadas nas leis do comportamento dos gases, de acordo com temperatura e pressão (SILVA et al., 1999).

Sendo assim, o valor do atraso é obtido por meio de equações matemáticas que descrevem a realidade física da refração (seção 3.1) e do atraso (seção 3.2), que tem como valores de entrada os parâmetros atmosféricos (seção 3.3). Ambos, equações e parâmetros, quando aplicados a modelos específicos (seção 3.4), geram valores do atraso em função da localidade (latitude, longitude e altitude) e época (data e hora). Um parâmetro derivado a partir do atraso é o vapor d'água integrado, o IWV (seção 3.2.1), primordial no que concerne a contribuição da Geodésia na área GNSS Meteorologia. As pesquisas e melhorias na modelagem do atraso contribuem diretamente com a modelagem do IWV.

Nessa seção, além das características e passos para a modelagem do atraso, também será apresentada a determinação do atraso a partir do posicionamento GNSS (seção 3.5). Serão indicadas algumas referências e endereços de produtos públicos e gratuitos (seção 3.6) que disponibilizam valores do atraso que podem ser aplicados pelo usuário para a época e local a qual necessite.

\subsection{Refração do Sinal GNSS devido à atmosfera neutra}

A refração é um fenômeno físico em que uma onda eletromagnética (luz visível ou onda de radiofrequência) muda de velocidade (direção e magnitude ou rapidez) de um meio a outro diferente (SMART, 1977). A onda também pode ser modelada por meio de um raio ótico ou raio eletromagnético. Esse fenômeno de desvio do raio pode ser determinado pela Lei de Snell (HECHT, 2002). A refração devido à atmosfera neutra ocorre por se propagar entre parcelas de ar com diferentes condições de pressão, temperatura e umidade.

Os efeitos atmosféricos neutros que afetam a propagação do sinal incluem atenuação, cintilação e atraso. A atenuação está ligada à diminuição da potência da onda eletromagnética, exercida pelos componentes da atmosfera neutra, variando para cada frequência. Já a cintilação é uma oscilação abrupta na amplitude da onda eletromagnética, causada por irregularidades e variações bruscas no índice de refratividade (SPILKER Jr., 1996). Segundo Monico (2008), na frequência utilizada pelo GNSS esses efeitos são, em geral, relativamente pequenos e podem ser negligenciados, exceto para baixos ângulos de elevação (menores que $5^{\circ}$ ). Já o atraso é o efeito de maior magnitude para os sinais GNSS.

O atraso da atmosfera neutra é a variação no tempo de propagação do sinal GNSS, e normalmente é expresso em unidades de medida de distância (metros ao invés de segundos), ao ser implicitamente multiplicado pela velocidade da luz. O índice de refração, $n=c / v$ (em termos da velocidade $\mathrm{m}$ vácuo $c$ e a velocidade no ar), ou a refratividade, $N=10^{-6}(n-1)$, causa uma alteração na magnitude da velocidade (rapidez - medida escalar) da onda; por outro lado, o gradiente de refratividade altera a direção da velocidade da onda. Então, define-se o atraso pela diferença entre a distância geométrica, percorrida hipoteticamente pelo sinal no vácuo, e a trajetória do sinal que sofre os efeitos físicos da atmosfera terrestre. Logo, o atraso é dependente apenas das características termodinâmicas da atmosfera (SAPUCCI, 2001). 
A refratividade que impacta o sinal GNSS é a soma de duas componentes: a componente seca (dry) $N_{d}$ e a componente úmida (wet) $N_{w}$. O valor da refratividade é então determinado ao considerar os elementos que compõe cada parte da atmosfera neutra, possível devido ao comportamento diferenciado dos gases secos e do vapor d'água (THAYER, 1974; ESSEN; FROOME, 1951 apud TEUNISSEN; MONTENBRUCK, 2017). É possível obter $N$ em termos de componentes hidrostática e não hidrostática (MENDES, 1999; NIEVINSKI, 2009). De acordo com Mendes (1999), o termo que se refere à componente hidrostática, pode ser tratado de modo a depender apenas da densidade total da atmosfera e não da razão de mistura das componentes hidrostática e não hidrostática. Por outro lado, a componente não hidrostática está relacionada com a temperatura e a pressão do vapor d'água. A denominação "hidrostática" advém da suposição de equilíbrio hidrostático feita durante a integração zenital, conforme descrito abaixo.

\subsection{Atraso de propagação da onda eletromagnética}

A trajetória do sinal GNSS entre dois pontos será aquela percorrida no menor intervalo de tempo (Princípio de Fermat) (HECHT, 2002). Logo, considerando a atmosfera com diferentes camadas infinitesimais, o caminho percorrido pelo sinal do satélite (real) é curvado e único, definido por um índice de refração total (figura 3). Determinada a posição de um ponto ao longo do caminho do raio é possível calcular $n$ e o comprimento do raio (NIEVINSKI; SANTOS, 2010; NAFISI et al., 2012).

Figura 3 - Sinal GNSS ao se propagar na atmosfera, do satélite ao receptor, e o efeito do atraso de propagação da onda portadora do sinal GNSS. Imagem da Terra cedida por: http://www.casa.org.br/wp-content/uploads/2015/12/americado-sul.png.

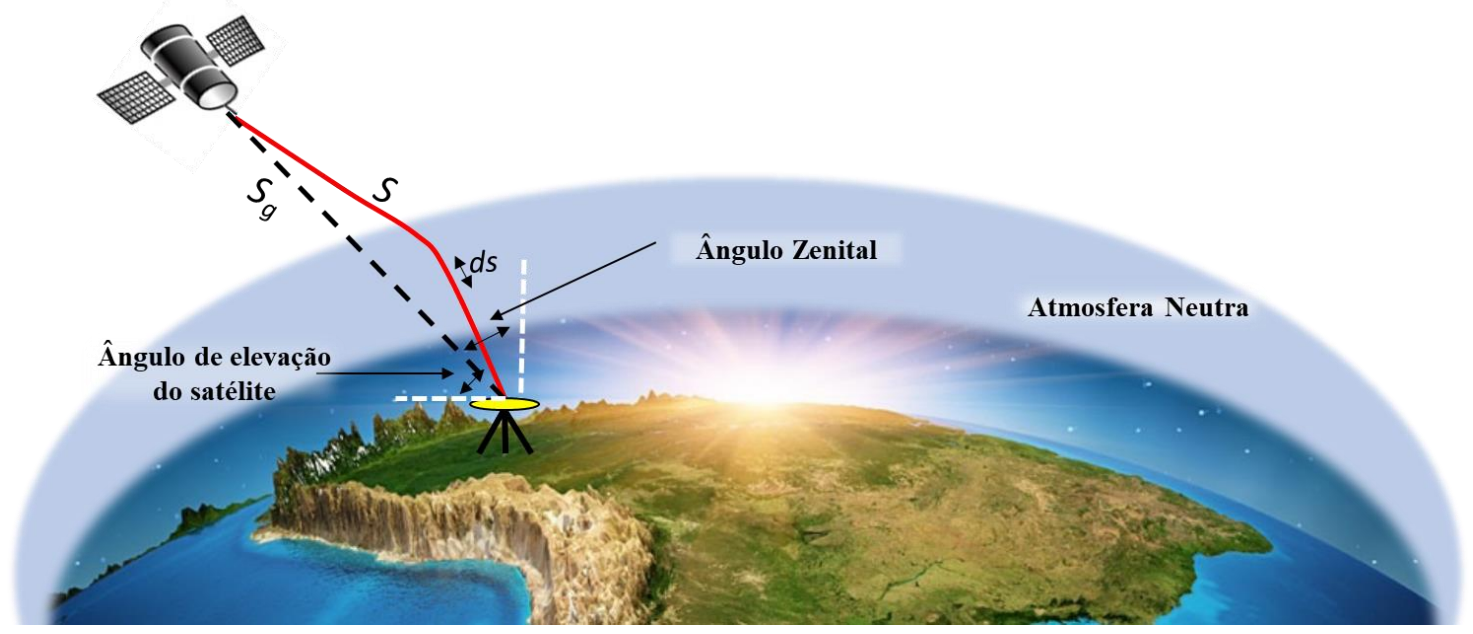

Fonte: Os autores (2020).

Na direção zenital $\left(90^{\circ}\right)$, a integração da refratividade é definida em relação à altitude, isto é, do perfil vertical de gases secos (hidrostáticos) e do vapor d'água sobre um local ou estação (TEUNISSEN; MONTENBRUCK, 2017; SAPUCCI, 2001). Assim, o atraso zenital irá variar em relação à altitude mínima de superfície $\left(h_{0}\right)(\mathrm{em} \mathrm{m})$, e a máxima - altitude máxima da atmosfera neutra $(h)(\mathrm{em} \mathrm{m})$, obtido pela integração da equação que modela da refratividade $N$ nos diferentes níveis de altitude. A componente hidrostática da refratividade depende apenas da densidade total do ar e seu atraso zenital correspondente $d_{h}^{Z}$ pode ser integrado de forma fechada ao se assumir que a atmosfera está em equilíbrio hidrostático, o que simplifica o modelo de $d_{h}^{Z}$ (SAASTAMOINEN, 1972; DAVIS et al., 1985).

Com essa simplificação da realidade física é possível determinar o atraso hidrostático com razoável precisão. Isso ocorre, pois, a pressão em superfície $\left(P_{0}\right.$, em $\left.\mathrm{hPa}\right)$ apresenta pouca variação em horas e quilômetros de distância. Esse modelo é considerado como modelo a priori de processamentos de dados GNSS, assim como base para a posterior obtenção da componente não-hidrostática (diferença com a componente total, $d_{n h}^{Z}=d^{Z}-d_{h}^{Z}$ ). Cabe ressaltar que a suposição de equilíbrio hidrostático é invocada apenas no cálculo do atraso zenital via pressão de superfície; nos casos em que aquela suposição é violada (por 
exemplo, durante um ciclone), o cálculo por integração é mais acurado pois dispensa a suposição de hidrostasia, apesar do nome.

A componente não-hidrostática do atraso zenital $\left(d_{n h}^{Z}\right)$ depende do vapor d'água (DAVIS et al., 1985). Suas medidas não podem ser realizadas na superfície, sendo necessário utilizar outros métodos. Diferente da componente hidrostática, a componente não hidrostática não pode ter reduções em seu modelo. Isso ocorre, pois, a pressão parcial do vapor d'água $\left(P_{w}\right)$ é muito variável com relação ao espaço e ao tempo, a solução exata se torna complexa, fazendo com que esse atraso seja de difícil predição.

Os sinais GNSS são recebidos em qualquer direção caracterizada pelo ângulo de elevação e azimute. Quando um sinal do satélite GNSS atinge a atmosfera neutra em um ângulo de incidência diferente do ângulo normal (ou zenital), o caminho do raio torna-se curvado devido à refratividade (seção 3.1). Quanto menor for o ângulo de elevação do satélite, maior será o impacto da refratividade nos sinais, e consequentemente nas medidas GNSS (seção 4). Assim, o atraso em qualquer direção é obtido em função: do tempo ( $t$ ); das coordenadas do receptor ( $\varphi, \lambda, h$ - latitude, longitude e altitude); e da direção do satélite ( $\varepsilon, \alpha$ - ângulo de elevação e azimute); isto é, $d \equiv f(t, \varphi, \lambda, h, \varepsilon, \alpha)$. O atraso na direção zenital (vertical) ( $\left.d^{z}\right)$ é um caso específico do atraso inclinado, cujo ângulo de elevação é o zênite, $\varepsilon=90^{\circ}$ (SAPUCCI, 2001; NIEVINSKI; SANTOS, 2010).

A maioria dos sinais dos satélites GNSS registrados nos receptores não atinge a direção do zênite, ocorrendo nas direções inclinadas, por isso o atraso precisa ser determinado na direção inclinada (linha de visada entre satélite e receptor). A determinação do atraso na direção inclinada é realizada através do traçado de raios (ou ray tracing), que permite determinar a trajetória que a onda eletromagnética percorreu e modelar a refração atmosférica sofrida (NIELL, 1996; BOEHM et al., 2006a; BOEHM et al., 2006b; HOBIGER et al., 2008a; NIEVINSKI, 2009; NIEVINSKI; SANTOS, 2010; SANTOS et al., 2012; LANDSKRON et al., 2018). Da razão entre o atraso zenital e o atraso inclinado resulta os fatores inclinados, $d / d^{z}$. Desses fatores surgem as chamadas funções de mapeamento $(m)$ que são modelos ajustados aos resultados do traçado de raios.

As funções de mapeamento (MARINI, 1972; NIELL, 1996) são mais aplicadas em trabalhos práticos devido à maior praticidade em relação à própria técnica do traçado de raio. Sendo assim, o modelo que descreve o atraso da atmosfera neutra em qualquer ângulo de elevação é expresso por $d=m_{h} \cdot d_{h}^{Z}+m_{n h} \cdot d_{n h}^{Z}$ (DAVIS et al., 1985; TEUNISSEN; MONTENBRUCK, 2017).

A magnitude do atraso é determinada de acordo com a espessura da camada neutra à qual o sinal atravessa até atingir a antena do receptor, ou seja, o ângulo de elevação entre satélite e receptor. Para ângulos próximos ao zênite $\left(90^{\circ}\right)$ o atraso de propagação da onda eletromagnética é da ordem de 2,3 m a 2,6 m, sendo até dez vezes ou mais para satélites nascentes ou poentes (quando menor que $5^{\circ}$ de elevação, por exemplo, o atraso é de $25 \mathrm{~m}$ ). Note na Figura 4 (a) que para ângulos de elevação menores que $3^{\circ} \mathrm{o}$ atraso inclinado pode atingir valores próximos a $60 \mathrm{~m}$. Esse atraso causa erros nas coordenadas finais do posicionamento GNSS, caso o mesmo não seja modelado de forma adequada (DAVIS et al., 1985; SAPUCCI, 2001; MONICO, 2008; NIEVINSKI; SANTOS, 2010; TEUNISSEN; MONTENBRUCK, 2017).

O atraso hidrostático tem a ordem de grandeza de 2,3 m no zênite e próximo ao horizonte (inferior a $5^{\circ}$ ) pode ultrapassar $45 \mathrm{~m}$, variando de acordo com a temperatura, altitude, latitude e a pressão atmosférica. Essa componente representa $90 \%$ do atraso total e sua variação temporal é pequena (Figura 4 (b), eixo secundário), da ordem de $1 \%$ durante várias horas. Já a componente não-hidrostática representa 10\% do atraso total, chegando a aproximadamente $35 \mathrm{~cm}$ no zênite e sendo superior a $9 \mathrm{~m}$ próximo ao horizonte (elevação inferior a $3^{\circ}$ ); porém, sua variação temporal e espacial é muito maior (Figura 4 (b)), atingindo cerca de $20 \%$ em poucas horas (SEEBER, 2003), resultado da variação da umidade do ar. 
Figura 4 - Variação do atraso da atmosfera neutra de acordo com o ângulo de elevação (a) e com o tempo (b), em relação às três componentes: total $\left(d\right.$ : Dtot), não-hidrostática $\left(d_{n h}\right.$ : Dnh) e hidrostática $\left(d_{h}:\right.$ Dh) para a estação NAUS (Manaus-AM).

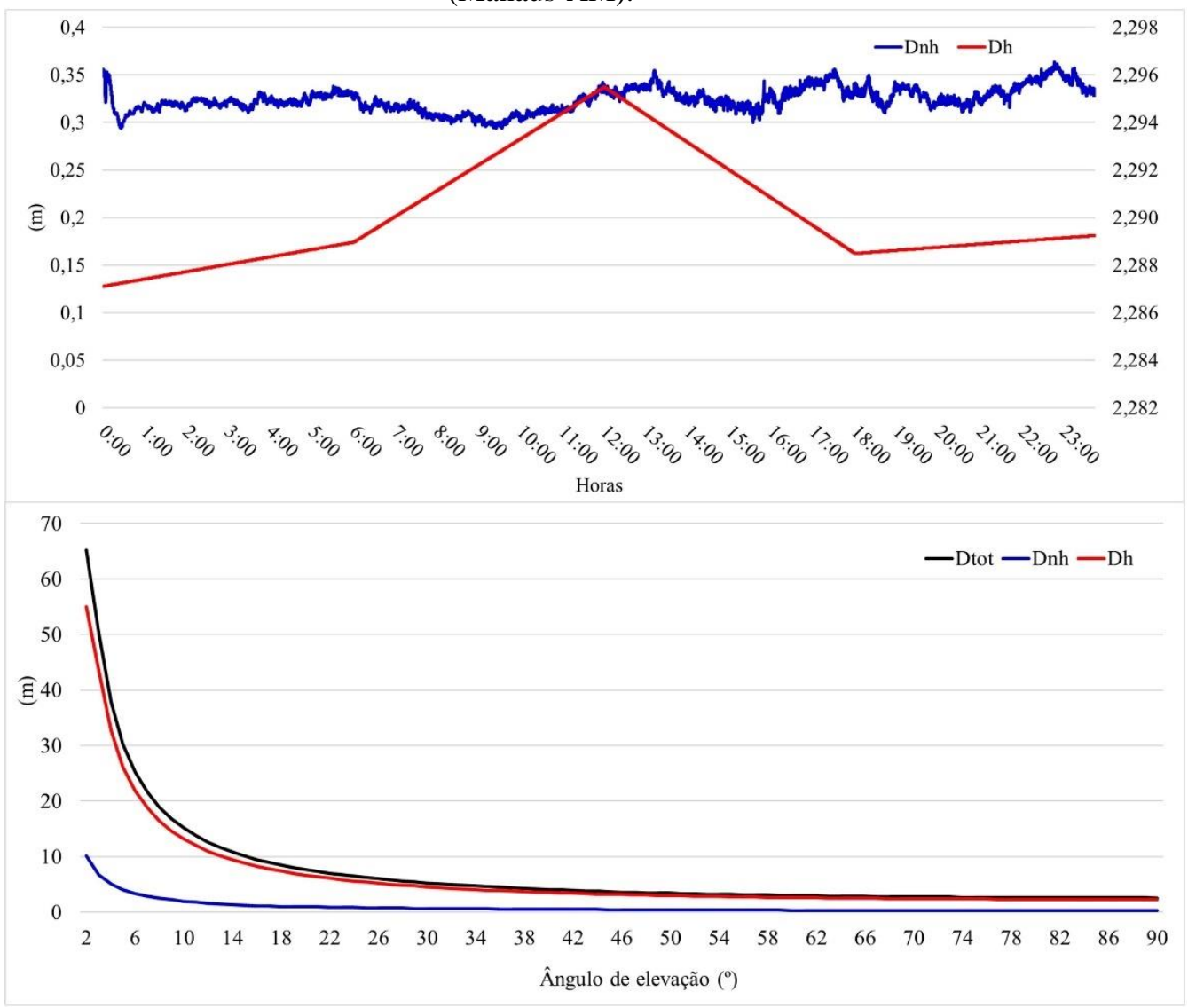

Fonte: Os autores (2020).

Segundo Teunissen e Montenbruck (2017), a atmosfera neutra é considerada um meio não dispersivo pois, tanto para a pseudodistância quanto para a fase, a influência da frequência sobre o seu efeito é inferior a $0,2 \mathrm{~mm}$, para todos os ângulos de elevação. A característica de não dispersão simplifica a modelagem do efeito de propagação sob a atmosfera neutra, já que esses efeitos são idênticos para a pseudodistância e fase da portadora. No entanto, esses efeitos não podem ser reduzidos por medidas de multifrequência, como no caso da ionosfera, sendo necessária uma modelagem adequada.

Assim, o atraso devido à atmosfera neutra varia de acordo com a concentração dos constituintes atmosféricos que o originam: pressão, temperatura e vapor d'água, parâmetro de mais difícil medida devido sua alta variabilidade e distribuição na atmosfera. As variações desses constituintes ocorrem em relação a sazonalidade (estações do ano) e a variação espacial. Por essa razão, o atraso e principalmente sua componente composta de vapor d'água, são considerados uma das principais fontes de erro na Geodésia Espacial.

\subsection{Parâmetros Atmosféricos: diferentes fontes e modelagem}

Os valores da concentração dos constituintes atmosféricos podem ser obtidos de forma direta ou indireta a partir de diferentes fontes. Essas fontes fornecem os dados de entrada para modelar a refratividade e por consequência o atraso de propagação do sinal devido a atmosfera neutra (SAPUCCI, 2001; MONICO, 2008; TEUNISSEN; MONTENBRUCK, 2017).

Medidas diretas da concentração dos constituintes atmosféricos, na extensão de toda a atmosfera, são difíceis de serem determinadas. Logo, a Meteorologia se faz uma forte aliada fornecendo essas informações por meio de diferentes fontes de dados de medidas independentes, como os seguintes tipos de observações: estações convencionais e automáticas de superfície (composta por diferentes sensores), estações de altitude como a sondagem atmosférica, por meio de radiossondas, bóias oceânicas, navios, dados de aeronaves; e dados de satélites geoestacionários meteorológicos (como o Geostationary Operational Environmental Satellite - 
GOES). As radiossondas se destacam, pois além da qualidade de suas medidas diretas da concentração dos constituintes atmosféricos, também o faz nos diferentes níveis da atmosfera. Esse fator é importante para o cálculo do atraso ao longo de toda a trajetória do sinal GNSS.

Os dados observados podem ser obtidos em diferentes centros internacionais, com dados de todo o globo, como: o National Oceanic and Atmospheric Administration (NOAA) (Weather|NOAA, 2020), Climate Data Store do European Centre for Medium-Range Weather Forecasts (ECMWF) (CDS, 2020); dados de radiossondas do Global Climate Observing System (GCOS) Reference Upper-Air Network (GRUAN) (GRUAN, 2020) e da University of Wyoming (Atmospheric Soundings, 2020). No Brasil, dois principais centros que disponibilizam esses dados são: o CPTEC/INPE (CPTEC, 2020) e o Instituto Nacional de Meteorologia (INMET) (INMET, 2020).

Entre as estações meteorológicas de superfície automáticas pode-se ressaltar aquelas instaladas próximas às estações GNSS. Essas estações são compostas por diversos sensores que medem temperatura, pressão atmosférica, umidade relativa, velocidade e direção do vento, entre outras variáveis. As informações medidas são registradas automaticamente, com intervalos de coleta similares aos dados GNSS (MONICO, 2006; SAPUCCI, et al., 2010), sendo essa sua principal vantagem. Visando GNSS-meteorologia (seção 4), assim como aplicações GNSS (seção 5), uma rede dessas estações meteorológicas automáticas foi instalada em estações da Rede Brasileira de Monitoramento Contínuo dos Sistemas GNSS (RBMC) no estado de São Paulo via projeto temático junto à FAPESP (Processo 2006/04008-2) (GNSS-SP).

Os parâmetros resultantes de modelos de Previsão Numérica de Tempo (PNT), são outra fonte de dados atmosféricos. Os modelos de PNT são compostos de teorias da física da atmosfera, modelos matemáticos e do estado inicial da atmosfera para então gerar o estado futuro da mesma. Esse estado inicial da atmosfera é fornecido pela assimilação de dados. Técnica que consiste em ajustar o estado inicial da atmosfera considerando os dados observados.

Os dados observados são combinados com as previsões de curto prazo do próprio modelo ("First Guess" - FG), gerando assim, condições iniciais (denominadas de análise) para novas integrações. Quando o modelo chega a um instante em que existe uma observação disponível, o estado previsto pelo modelo (background) é corrigido por essa observação (uma filtragem dos dados). Assim, a integração do modelo é reiniciada após essa correção, e esse processo é repetido para todas as observações disponíveis, sendo gerada uma nova análise para o modelo de PNT. O processo de assimilação de dados em um modelo de PNT é um procedimento cíclico ou iterativo (TALAGRAND, 1997 apud GONÇALVES, 1999; SAPUCCI, et al., 2005; SAPUCCI, et al., 2007a; VENDRASCO et al., 2016).

Pode-se destacar os dados de previsão dos parâmetros atmosféricos advindos dos modelos globais: Europeu - ECMWF (ECMWF, 2020); Canadian Meteorological Centre (CMC) (CANADA, 2020) e os modelos regionais do CPTEC/INPE (CPTEC/PNT, 2020). Isso requer uma grande quantidade e qualidade de dados, dentre as quais destacam-se radiossondas e outros sensores em bases terrestres e dados provindos de sensores remotos em satélites.

As recuperações climatológicas ou modelos de dados empíricos (ou teóricos), se apresentam como outra alternativa na modelagem do atraso. Esses modelos consideram a configuração média do comportamento atmosférico ao longo de anos de informações, ou seja, comportamento normal dos fenômenos atmosféricos (VIANELLO; ALVES, 2000). Como resultado disponibiliza valores "médios" dos constituintes atmosféricos. Esses modelos podem ter abrangência regional ou global, isto é, as informações utilizadas são compatíveis com a resolução espacial do modelo. Dentre os modelos globais mais atuais disponíveis para qualquer região e época pode-se citar: os modelos Globais de Pressão e Temperatura (GPT - Global Pressure and Temperature) (BOEHM et al., 2007); GPT2 (LAGLER et al., 2013); GPT2w (GPT wet) (BOEHM et al., 2014); GPT3 (LANDSKRON et al., 2018). Esses modelos se encontram disponíveis em: VMF Codes (2020).

O Brasil tem extensão territorial com dimensões continentais, a qual possui clima muito distinto, que varia de acordo com as diferentes regiões e épocas do ano. Isso implica condições climáticas muito distintas num mesmo dia, horas do dia e de acordo com a região. O clima brasileiro apresenta forte influência da floresta Amazônica e dos oceanos na circulação atmosférica, pois a partir da floresta são emitidos gases e vapor d'água - variáveis ao longo do ano - que causam uma variação na densidade de gases e vapor d'água que compõem a 
atmosfera neutra. A qualidade dos dados e modelos atmosféricos têm impacto direto na acurácia do atraso de propagação calculado, as vantagens e desvantagens de cada fonte e o impacto na qualidade do atraso são apresentados na próxima seção.

\subsection{Modelagem do atraso}

Ao se tratar de modelagem do atraso precisa ficar claro que se trata de dois aspectos principais, os dados e os modelos (compostos por simplificações da refratividade e por equações). De posse das equações matemáticas (seção 3.2) e dos parâmetros atmosféricos (seção 3.3), algumas técnicas podem ser aplicadas para a obtenção do atraso, dando origem a diferentes modelos, tanto na direção zenital quanto inclinada. Essas técnicas vêm sendo aprimoradas com o passar dos anos.

A determinação do atraso se dá por diferentes estratégias, desde as mais utilizadas devido a sua facilidade de aplicação, porém com pior precisão, às mais sofisticadas e acuradas (MONICO et al., 2009). Essas estratégias podem ser divididas basicamente em quatro: modelos empíricos do atraso na direção zenital combinado a uma função de mapeamento; funções de mapeamento do atraso, as quais relacionam o atraso zenital ao ângulo de elevação do satélite; o atraso obtido diretamente, a partir do traçado de raio; e o atraso estimado no posicionamento GNSS. O mais rigoroso, o traçado de raio (raytracing), devido a sua complexidade (alto custo computacional e de tempo) (HOBIGER et al., 2008a; HOBIGER et al., 2008b; NIEVINSKI, 2009; NIEVINSKI; SANTOS, 2010).

De posse dos valores da concentração dos constituintes atmosféricos é possível calcular o atraso, quer seja aplicado a modelos empíricos, que consideram medidas de superfície, ou por diferentes metodologias que considerem a integração da refratividade em todos os níveis da atmosfera neutra (vertical ou inclinada). As modelagens do atraso mais simples para o usuário são os modelos empíricos, ou seja, modelo zenital e função de mapeamento e fonte de dados empíricos (modelos de dados empíricos ou blind models). Nesse caso, as recuperações climatológicas GPT (BOEHM et al., 2007; LAGLER et al., 2013; BOEHM et al., 2014; LANDSKRON et al., 2018).

Esses modelos fornecem valores aproximados do atraso e de baixa resolução. Embora representem uma aproximação, seus defeitos são minimizados quando empregados métodos de ajustamento para compensar os resíduos advindos dessa modelagem (SAPUCCI, 2001; TEUNISSEN; MONTENBRUCK, 2017). Dentre os modelos, pode-se citar: Hopfield (1969); Saastamoinen (1973); Davis et al. (1985); Ifadis (1986); Askne e Nordius (1987), entre outros. Porém, os modelos mais utilizados são o modelo de Hopfield (SEEBER, 2003) e Saastamoinen (SAASTAMOINEM, 1972), os quais apresentam resultados satisfatórios em curtos intervalos de tempo.

A modelagem do atraso a partir de medidas dos parâmetros atmosféricos em superfícies, como os advindos das estações meteorológicas convencionais ou automáticas, apresentam resultados mais precisos que os empíricos. A metodologia se dá pela aplicação desses dados aos modelos empíricos do atraso como ao Saastamoinen. sendo caracterizados como híbridos. Pode-se citar o modelo UNB3m da University of New Brunswick (LEANDRO et al., 2006) e um desenvolvido na FCT-UNESP (LIMA et al., 2019).

A aplicação das constituintes atmosféricas obtidas pelas estações meteorológicas de altitude, medidas pelas radiossondas, nas equações do atraso zenital pela integração da refratividade fornecem valores com alta acurácia. Porém, a baixa distribuição das estações, em algumas regiões do globo como no Brasil, e o intervalo temporal de medidas (duas vezes dia), se apresentam como limitações para o uso prático dessa metodologia. Essa fonte é mais usada para investigação científica e avaliação da qualidade do atraso obtido por outras estratégias.

Nesse cenário, a metodologia que considera os parâmetros atmosféricos resultantes de modelos de PNT aplicados às equações da refratividade se apresentam como uma alternativa promissora para o cálculo do atraso. Os modelos citados fornecem os valores (pressão, temperatura e umidade) para o cálculo do atraso para dada localidade (contido em uma grade de resolução espacial específica para cada modelo) e momento (resolução temporal do modelo), tanto no passado (base de dados regressos) ou futuro (previsões de tempo). Uma das principais vantagens é a resolução espaço-temporal: quanto maior é a resolução, maior precisão essa metodologia apresenta, disponibilizando o atraso tanto no passado (base de dados regressos) quanto no futuro 
(previsões de tempo). Deste modo, a técnica de traçado de raios aliada aos dados de entrada obtidos a partir da PNT pode representar uma modelagem ainda mais rigorosa para o atraso (NIEVINSKI, 2009; NIEVINSKI; SANTOS, 2010).

Tratado o atraso na direção zenital, as funções de mapeamento são aplicadas para obtenção do atraso na direção de visada do satélite (direção satélite-receptor). Inicialmente um modelo simples foi aplicado, $\frac{1}{\sin (e)}$, mas para ângulos de elevação de até $20^{\circ}$, é inadequada, pois apresenta discrepâncias significativas (erro de 1\%, cerca de $45 \mathrm{~cm}$ no atraso inclinado). Na busca de funções precisas para ângulos de elevação mais próximos ao horizonte, outras funções foram desenvolvidas: Marini (1972), Chao (1974) apud Davis (1985), Davis (1985), Herring (1992), Niell (1996) e Niell (2000).

Como no caso dos modelos do atraso zenital, as funções empíricas, ou de recuperação climatológica, não se apresentam adequadas à todas as aplicações, principalmente quando melhor acurácia é requerida. Por isso, modelos de PNT passaram a ser aplicados à técnica de traçado de raio, e pela razão entre o atraso inclinado e o zenital, ambos advindos da PNT, originaram-se funções de mapeamento mais promissoras. Com o passar dos anos, tais funções foram aprimoradas apresentando melhor qualidade na determinação do atraso, sendo possível citar: Isobaric Mapping Function (IMF) (NIELL, 2001); Vienna Mapping Function (VMF) (BOEHM et al., 2004); Global Mapping Function (GMF) (BOEHM et al., 2006a); VMF1 (BOEHM et al., 2006b e 2007); UNB-VMF1 (URQUHART, 2010; URQUHART et al., 2010); VMF3 (LANDSKRON et al., 2018); Brazilian Mapping Function (BMF) (GOUVEIA, 2019). A GMF é uma função híbrida resultante da recuperação atmosférica a partir do ECMWF Re-analysis of the global Atmosphere and surface conditions for 45-years (ERA40).

A qualidade dos dados e modelos atmosféricos têm impacto direto na acurácia do atraso de propagação calculado. Cada fonte de dados apresenta vantagens e desvantagens, seja por conta de sua resolução espacial, resolução temporal ou devido a qualidade.

\section{PRODUTOS ATMOSFÉRICOS: BENEFÍCIO DA GEODÉSIA ESPACIAL PARA A METEOROLOGIA (GNSS-METEOROLOGIA)}

Inicialmente, na década de 1950, o cálculo do vapor d'água atmosférico era determinado a partir das radiossondas. Embora as radiossondas apresentem medidas nos diferentes níveis da atmosfera (da superfície ao topo da atmosfera neutra), elas apresentam a baixa resolução espaço-temporal (GUEROVA et al., 2016). No que tange às variações bruscas do vapor d'água, que ocorrem em locais específicos e com curtíssimo prazo (30 minutos), tal técnica não se apresenta adequada. Tralli e Lichten (1990) aplicaram a técnica GNSS para realizar sondagem atmosférica, inicialmente denominada GPS-Meteorologia. Com o passar dos anos e ampliação dos sistemas de navegação, a técnica passou a ser denominada GNSS-Meteorologia. Muitas pesquisas foram desenvolvidas na área GNSS-Meteorologia: Sapucci (2005), Sapucci et al. (2007a), Sapucci et al. (2007b), Smith et al. (2007), Yan et al. (2009), Sapucci et al. (2010) e Guerova et al. (2016). Nesse cenário, o Global Geodetic Observing System (GGOS) contribui com o estado da arte da GNSS-Meteorologia, pois em consonância com o International GNSS Service (IGS) fornece produtos do atraso da atmosfera neutra.

\subsection{Estimativas do Vapor d'água integrado (Precipitable Water Vapour - PWV) usando dados GNSS}

A quantidade de vapor d'água atmosférico sobre um dado ponto na superfície terrestre é definida como uma massa de vapor d'água integrada na direção vertical, por unidade de área, denominada IWV, expressa em quilograma por metro quadrado $\left(\mathrm{kg} / \mathrm{m}^{2}\right)$. Outra forma de expressar uma quantidade de vapor d'água integrada é através da altura de uma coluna equivalente de água líquida ou água precipitável (Precipitable Water - PW) em unidade de milímetros. Com os estudos da relação entre o IWV GNSS e a precipitação, medida também dada em milímetro da coluna d'água, convencionou-se utilizar o termo PWV (Precipitable Water Vapor). Dessa forma, a relação entre IWV e $P W V$ (ou $P W$ ) é obtida considerando a densidade da água líquida $\left(\rho_{a}\right)$, $P W V=\frac{I W V}{\rho_{a}}($ BEVIS et al., 1992; SAPUCCI, 2001). 
Medidas de PWV sobre um determinado local são obtidas pela integração da densidade de vapor d'água ou umidade absoluta $\left(\rho_{w}\right)$, desde a superfície $\left(h_{0}\right)$ até a altitude $(h)$ em que a concentração do vapor d'água é desprezível, em uma coluna de ar de seção transversal unitária, $P W V=\int_{h_{0}}^{h} \rho_{w} d h$ (VIANELLO; ALVES, 1991; SAPUCCI, 2001; SAPUCCI, 2005).

A determinação numérica dessa integral requer a utilização de alguns equipamentos sofisticados. Porém, determinado o $d_{n h}^{Z}$ é possível obter do $P W V$, a partir da relação dada por $\Psi\left(\mathrm{kg} / \mathrm{m}^{3}\right)$, ou seja, $P W V=$ $d_{n h}^{Z} \cdot \Psi$, e $\Psi=\frac{10^{6}}{R_{w}\left[k_{2}+\frac{k_{3}}{T_{m}}\right]}$.Essa relação considera a massa molar da molécula de água $\left(R_{w}\right)$ e a temperatura média da atmosfera úmida ( $\left.T_{m}, \mathrm{~K}\right)$ (DAVIS et al., 1985; BEVIS et al., 1992; SAPUCCI, 2001; SAPUCCI, 2014a ). Sapucci (2014a) apresentou um modelo de Tm específico para ser utilizado na obtenção do PWV a partir de dados GNSS no Brasil. O que é importante para a aplicação dessa técnica é utilizar receptores de dupla frequência e que dados de pressão a superfície de boa precisão (melhor que $0.5 \mathrm{hPa}$ ) sejam medidos com um barômetro instalado junto a antena GNSS. Mais detalhes sobre a metodologia utilizada podem ser encontrados com bastante riqueza de informações em Sapucci (2001).

Em Sapucci et al., (2019) foi reportando uma aplicação inovadora dos dados do PWV advindos de receptores GNSS, que é a sua utilização para prever eventos extremos de precipitação em atividades em previsão imediata (nowcasting), tendo como principal finalidade a emissão de alertas sobre a ocorrência iminente de uma tempestade. O foco é a população vulnerável aos riscos de perda da vida e de prejuízos materiais, induzindo ações efetivas e antecipadas de prevenção e redução dos danos na ocorrência desses fenômenos. Entre os desastres naturais, aqueles gerados pelas tempestades severas, tais como as inundações e deslizamentos de encosta, são os que merecem maior atenção, pois são os que apresentam maiores ocorrências no Brasil. Os impactos desses à sociedade são significativos, gerando grandes prejuízos econômicos e perdas irreparáveis às famílias, o que evidencia a importância do aprimoramento dessa técnica.

\subsection{Tomografia-GNSS do vapor d'água}

A tomografia é um método aplicado para obter quantidades a partir de medições na direção inclinada (slant), tornando possível estimar uma estrutura 2D ou 3D. Este método é aplicado em diferentes áreas, como também para reconstruir a estrutura 3D da refratividade não-hidrostática e total. $\mathrm{O}$ atraso gerado pela influência do vapor d'água atmosférico na direção inclinada $\left(d_{n h}^{S}\right)$ é definido como sendo a integral da refratividade atmosférica da componente não-hidrostática na trajetória do sinal entre a antena de um satélite GNSS e a antena receptora. Sendo assim, a técnica de tomografia GNSS, que considera a aplicação da Geodésia e do GNSS, requer que o atraso inclinado seja medido por várias estações GNSS, de preferência próximas (poucos quilômetros de distância). Logo, permite determinar a distribuição do atraso da atmosfera neutra e consequentemente do vapor d'água, de IWV e PWV (BOHM; SCHUH, 2013).

O vapor d'água atmosférico integrado na direção inclinada é definido como sendo a integral da umidade absoluta $\left(\rho_{w}\right)$ ao longo da trajetória entre o satélite-receptor. De forma similar ao caso do atraso no zênite $\left(d_{n h}^{Z}\right)$ é possível converter valores do atraso troposférico na direção inclinada em valores do IWV inclinado, o SIWV (Slant IWV) (SAPUCCI, 2001).

Na estimativa GNSS do $d_{n h}^{S}$ a atmosfera, acima das estações GNSS, precisa ser parametrizada, que consiste em usar voxels. A parametrização por voxel implica dividir a atmosfera em caixas, locais onde a refratividade é considerada constante. Logo, o $d_{n h}^{S}$ por tomografia-GNSS será obtido por meio de combinação linear da refratividade de todos os voxels, na direção satélite-receptor (BOHM; SCHUH, 2013).

$\mathrm{O}$ atraso gerado pela influência do vapor d'água atmosférico na direção inclinada $\left(d_{n h}^{S}\right)$ apresenta maior dificuldade de ser estimado do que o atraso na direção zenital $\left(d_{n h}^{Z}\right)$. No último caso, todas as observações (inclinadas) são mapeadas na direção zenital via uma função de mapeamento apropriada. Apenas um valor é estimado num determinado intervalo de tempo. A estimativa nesse intervalo de tempo é aproximadamente uma média do atraso em todas as direções, proporcionando alta redundância. Na direção inclinada, estima-se um valor para cada linha de visada, num determinado período. Isso ocasiona uma redução na redundância e, por consequência, aumenta a influência de alguns erros, como os ruídos provenientes da 
instabilidade dos osciladores nos receptores e nos satélites GNSS, erros nas efemérides e a ocorrência do multicaminho dos sinais, dentre outros. No entanto, valores do $d_{n h}^{S}$ são capazes de gerar campos tridimensionais da distribuição do vapor d'água (MACDONALD; XIE, 2000), introduzindo uma valiosa informação sobre a distribuição vertical dessa variável para assimilação nos modelos PNT (KUO et al., 1996).

Embora promissora, a técnica de tomografia-GNSS apresenta limitações, as quais permitem um campo de investigações e pesquisas. Uma das limitações é a geometria dos satélites "fraca", uma vez que a tomografiaGNSS requer um grande volume de raios em todas as direções. Outro ponto a ser considerado é quanto ao sistema de equações mal condicionado, que pode ser solucionado ao aplicar medidas de refratividade a priori, advindos de modelos de PNT ou de radiossondas, por exemplo. Outra limitação ocorre com poucos raios ou ausência desses em um voxel, devido a mudança da geometria dos satélites ao longo de um dia. Nesses casos, estratégias precisam ser aplicadas, como restringir a refratividade de um voxel considerando a vizinhança ou método mais robusto ao aplicar o filtro de Kalman (BOHM; SCHUH, 2013).

Tratando adequadamente as limitações, a tomografia-GNSS é uma ferramenta promissora na detecção da alta variabilidade espaço-temporal do vapor d'água. Diferentes trabalhos atuais apresentam as melhorias quanto à técnica: Bender et al. (2011), Brenot et al. (2020), Zhang et al. (2020) e Moeller et al. (2020). No Brasil, tais estudos ainda não foram desenvolvidos.

\subsection{Perfis atmosféricos advindo da técnica de Rádio Ocultação GNSS}

A técnica de rádio ocultação (RO) começou a ser empregada na década de sessenta em missões de explorações planetárias (FJELDBO et al., 1969). No entanto, com o desenvolvimento do GNSS e dos satélites de órbita baixa (LEO, Low Earth Orbit), a RO passou a ser utilizada para a exploração e investigação da atmosfera terrestre (KURSINSKI, 1997). De forma simplificada, a ocultação é o fenômeno no qual um corpo celeste deixa de ser visível devido à sobreposição de um outro. Porém, devido à ação da atmosfera, o sinal ou luz emitida pelo objeto oculto é capaz de chegar ao receptor, transportando também informações da composição atmosférica.

$\mathrm{Na} \mathrm{RO}$ a atmosfera terrestre refrata o sinal transmitido pelo GNSS permitindo que o mesmo chegue ao receptor instalado no satélite LEO, mesmo estando ocultos pela Terra. A refração sofrida pela propagação do sinal na atmosfera (ionosfera e atmosfera neutra) permite o cálculo dos índices de refração da atmosfera e, a partir destes, é possível extrair perfis atmosféricos como, por exemplo, umidade, pressão, temperatura e densidade de elétrons (KURSINSKI et al., 2000; HAJJ et al., 2002; JEREZ, 2020; MORAES, 2020), denominando RO-GNSS.

Várias missões vêm sendo desenvolvidas incluindo receptores de RO, dentre elas destaca-se a missão COSMIC (Constellation Observing System for Meteorology, Ionosphere and Climate) (COSMIC, 2020) e mais recentemente a COSMIC-2 (COSMIC, 2020), lançada no dia 25/06/2019. Com os dados dessas missões podem ser obtidos perfis atmosféricos para todo o globo terrestre, inclusive em regiões remotas em que outras técnicas não poderiam ser utilizadas. Diversas pesquisas têm sido realizadas nas mais diversas áreas empregando dados de RO, como por exemplo em modelos climatológicos, modelos ionosféricos, detecção de desastres naturais, etc.

Considerando a assimilação de dados, os perfis atmosféricos advindos da RO-GNSS têm desempenhado um papel importante, o que tem justificado constantes investimentos visando a evolução da técnica nos últimos anos, tanto na resolução vertical e na precisão (menores incertezas) quanto na sensibilidade das variações atmosféricas (BANOS et al., 2018). Essas melhorias estão disponíveis na constelação de satélites dedicados a RO-GNSS e são atribuídas ao COSMIC-2. Esse projeto é uma parceria da NASA com diversas agências espaciais e o INPE. Nessa fase foram lançados seis satélites visando a contribuir para melhor observar a região equatorial, na qual os eventos mais extremos de precipitação são observados e os modelos apresentam deficiências em prevê-los adequadamente. O grande limitador para pesquisas que visavam estudar a contribuição dos perfis de RO-GNSS na melhoria da previsão de eventos intensos de precipitação era a pequena quantidade de dados de RO-GNSS durante as tempestades, pois a base era escassa na região tropical onde se concentram as mais fortes tempestades. Com o COSMIC-2 em operação isso deverá ser minimizado, viabilizando esse tipo de estudo. No entanto, para essa aplicação é necessário um processamento adequado dos 
dados na obtenção dos perfis de RO-GNSS, pois a assinatura da ocorrência das tempestades nos perfis atmosféricos pode ser confundida com ruídos e eliminada no processamento convencional. Uma nova abordagem no processamento desses dados é uma demanda importante da Meteorologia para a Geodésia. Essa melhor sensibilidade dos dados de RO-GNSS em um processamento aprimorado, associada com a maior disponibilidade sobre a região tropical, ou mesmo associada com dados advindos de receptores em bases terrestres com aplicação do PWV, configura uma nova ferramenta de detecção de eventos atmosféricos extremos e requer uma nova abordagem no processamento e uso desses produtos, sendo esse um desafio importante a ser enfrentado, pois está na vanguarda dos trabalhos nesse tema.

\section{PRODUTOS DISPONÍVEIS DO ATRASO E PESQUISAS RELACIONADAS}

$\mathrm{Na}$ busca em minimizar o atraso da atmosfera neutra do posicionamento GNSS ou aumentar a resolução espaço-temporal na quantificação do vapor d'água atmosférico, muitos trabalhos vêm sendo desenvolvidos. Estes contemplam tanto investigações científicas quanto produtos de fácil aplicação disponíveis ao usuário (quadro 1).

Modelos empíricos são disponibilizados por meio de suas equações e dados atmosféricos padrão, o usuário pode se utilizar desses modelos e melhorá-los aplicando outras fontes de dados que podem apresentar melhorias na modelagem do atraso (LIMA, 2019). Para aplicações em tempo real, podem ser aplicados os modelos empíricos, os híbridos e os resultantes da PNT. Uma vez que essas informações podem ser disponibilizadas antes mesmo do início do processamento. Como no caso da navegação aérea, agricultura de precisão, veículos autônomos, entre outros.

Para aplicações que requerem nível de qualidade alta (poucos centímetros ou até decímetros) os modelos empíricos ou híbridos podem não ser apropriados, pois não são capazes de modelar as variações do atraso (alta variação de pressão, temperatura e vapor d'água) (SAPUCCI, 2006). Isto ocorre, pois, as coletas das observações meteorológicas utilizadas para o desenvolvimento desses modelos globais foram realizadas, em sua maioria, no hemisfério norte. Por terem poucas estações meteorológicas no hemisfério sul, na época de coleta, tais valores podem apresentar grandes diferenças em relação aos demais encontrados para essas variáveis na região sul foram adotados valores empíricos para todo o globo.

A modelagem, por meio das diferentes maneiras de calcular o atraso (zenital e inclinado) e o PWV é apresentada na Figura 5, considerando as diferentes fontes de dados e modelos do atraso (incluindo as funções de mapeamento).

Estudos realizados no território brasileiro com diferentes tipos de posicionamento, regiões e épocas exemplificam a baixa qualidade desses modelos (ALVES et al., 2006a, 2006b, 2007a, 2007b, 2015; DALBELO et al., 2006; OLIVEIRA, 2013; OLIVEIRA et al., 2014a e 2014b; ABREU et al., 2014; GOUVEIA, 2013; GOUVEIA, et al., 2014; 2019; 2020; SETTI JR et al., 2016; LIMA, 2019) e destacam a acurácia de dados meteorológicos e modelos de PNT regionais. Cabe destacar que um fator preponderante é o clima tropical desta região, que apresenta bruscas variações de temperatura, pressão e principalmente de umidade ao longo das estações do ano. Diante disso, o Brasil se torna uma região propícia para tais investigações. Isto é devido à forte influência da floresta amazônica, que faz com que sejam encontrados no mesmo período do ano, ao longo de um dia, diferentes valores de vapor d'água, de temperatura e de pressão, de acordo com a localidade. Modelos teóricos geralmente são empregados de forma restrita para realizar correções a priori na estimativa do atraso a partir de processamentos de dados das observáveis GNSS (SAPUCCI, 2001; MARQUES, 2012).

No âmbito do IWV, a sua qualidade depende da modelagem da componente não hidrostática zenital do atraso e da temperatura média. Todas as melhorias e desenvolvimentos da determinação do atraso corroboram com a melhoria do IWV, sendo esse o produto disponibilizado a meteorologia para a assimilação de dados e aplicação nos modelos de PNT (SAPUCCI et al., 2007b; YAN et al., 2009; ROHM et al., 2014). Nesse cenário, os perfis de RO-GNSS, como já destacado, têm grande e importante contribuição. Trabalhos que visam tanto melhoria das técnicas aplicadas, quanto dos dados têm sido desenvolvidas (SAPUCCI et al., 2014b). Uma área de grande importância da aplicação do IWV são as investigações quanto às mudanças climáticas e eventos extremos (CAMPOS, 2018; SAPUCCI, 2019) (uma tese de doutorado em 
desenvolvimento na FCT-UNESP).

Figura 5- Metodologia da modelagem do atraso da atmosfera neutra, considerando as diferentes fontes de dados (empíricos, superfície, altitude, PNT e Rádio ocultação) e diferentes modelos do atraso zenital e inclinado, assim como a técnica do traçado de raio para obtenção do atraso inclinado ou das funções de mapeamento.

Fonte dos parâmetros atmosféricos Modelos do atraso

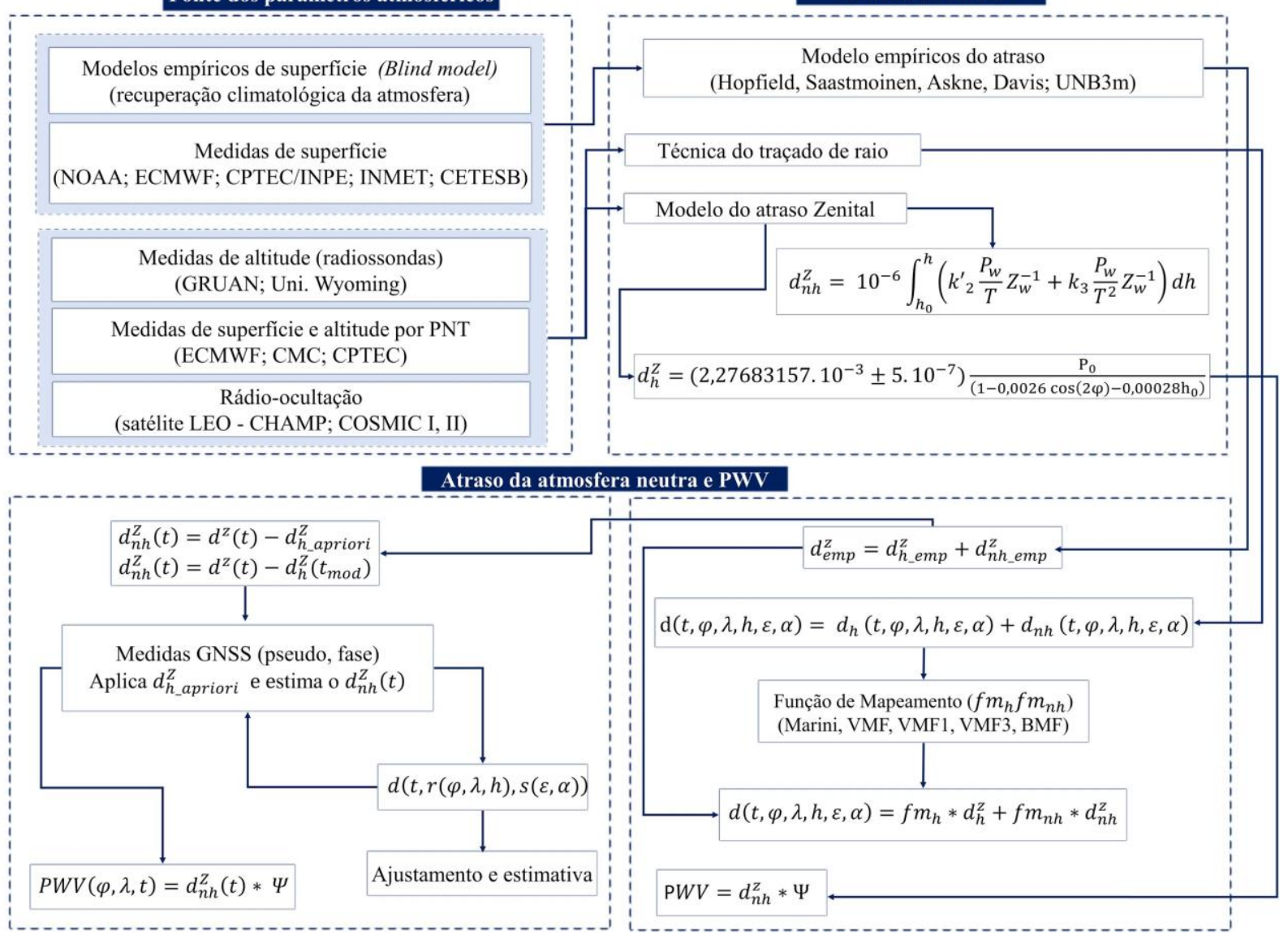

Fonte: Os autores (2020).

O Grupo de Estudos em Geodésia Espacial (GEGE) da Universidade Estadual Paulista (Unesp) (https://www.fct.unesp.br/\#!/pesquisa/grupos-de-estudo-e-pesquisa/gege/home/), sobre o eixo de investigação da modelagem do atraso de propagação GNSS devido à atmosfera neutra, apresenta-se como um centro brasileiro de excelência nesse tema. O GEGE contempla boa parte das pesquisas, assim como parcerias com outros pesquisadores da área. Metodologias cada vez mais aprimoradas vem sendo desenvolvidas, com resultados promissores, no que tange: ao cálculo do atraso de propagação e sua minimização nos diferentes métodos de posicionamento GNSS; na estimativa do IWV aplicado na investigação de mudanças climáticas e eventos extremos; e na obtenção de perfis atmosféricos, por medidas do vapor d'água por RO-GNSS (HOLZSCHUH et al., 2010). Os principais produtos do atraso da atmosfera neutra e do IWV disponibilizados, tanto no âmbito internacional quanto nacional, são apresentados no quadro 1. São destacados os centros que os disponibilizam, algumas características e seus respectivos endereços eletrônicos. 
Quadro 1 - Produtos do atraso e do IWV disponibilizados, principais características e seus endereços eletrônicos.

\begin{tabular}{|c|c|c|c|}
\hline & Produto & Características & Endereço \\
\hline $\begin{array}{l}\mathrm{I} \\
\mathrm{n}\end{array}$ & $\begin{array}{l}\text { IGS/ZTD } \\
\text { GNSS }\end{array}$ & $\begin{array}{l}d^{Z}, \text { GMF (elevação } 7^{\circ} \text { ) } \\
\text { Resolução e extensão temporal: } 5 \mathrm{~min}(24 \mathrm{~h} / \mathrm{dia}) \\
\text { Resolução e extensão espacial: rede IGS }\end{array}$ & $\begin{array}{l}\text { ftp://cddis.gsfc.nasa } \\
\text {.gov/gnss/products/t } \\
\text { roposphere/ }\end{array}$ \\
\hline $\begin{array}{l}\mathrm{t} \\
\mathrm{e} \\
\mathrm{r} \\
\mathrm{n}\end{array}$ & $\begin{array}{l}\text { GGOS/ZTD } \\
\text { GNSS }\end{array}$ & $\begin{array}{l}d^{Z}, d_{n h}^{Z}, \mathrm{VMF}\left(\text { elevação } 7^{\circ}\right) \\
\text { Resolução e extensão temporal: } 5 \mathrm{~min}(24 \mathrm{~h} / \mathrm{dia}) \\
\text { Resolução e extensão espacial: rede IGS }\end{array}$ & $\begin{array}{c}\text { http://ggos.org/en/m } \\
\text { ap/ }\end{array}$ \\
\hline $\begin{array}{l}\mathrm{a} \\
\mathrm{c} \\
\mathrm{i} \\
\mathrm{o}\end{array}$ & $\begin{array}{c}\mathrm{VMF} \\
\text { Raytracer+PNT/ECMWF }\end{array}$ & $\begin{array}{l}\qquad d_{h}^{Z}, d_{n h}^{Z}, m f_{h}, m f_{n h} \\
\text { Resolução e extensão temporal: } 06 \mathrm{~h}(24 \mathrm{~h} / \mathrm{dia}) \\
\text { Resolução e extensão espacial: rede global IGS }\end{array}$ & $\begin{array}{l}\text { https://vmf.geo.tuwi } \\
\text { en.ac.at/ }\end{array}$ \\
\hline $\begin{array}{l}\mathrm{a} \\
1\end{array}$ & $\begin{array}{c}\text { UNB_VMF1 } \\
\text { Raytracer+PNT/NCEP }\end{array}$ & $\begin{array}{l}\qquad d_{h}^{Z}, d_{n h}^{Z}, m f_{h}, m f_{n h} \\
\text { Resolução e extensão temporal: } 06 \mathrm{~h} \text { (24h/dia) } \\
\text { Resolução e extensão espacial: rede global IGS }\end{array}$ & $\begin{array}{l}\text { http://unb- } \\
\text { vmf1.gge.unb.ca/Pr } \\
\text { oducts.html }\end{array}$ \\
\hline $\begin{array}{l}\text { A } \\
\mathrm{m} \\
\text { é } \\
\mathrm{r}\end{array}$ & $\begin{array}{l}\text { SIRGAS/ZTD } \\
\text { GNSS }\end{array}$ & $\begin{array}{l}\text { VMFs (elevação } 3^{\circ} \text { ) } \\
\text { Resolução e extensão temporal: } 60 \text { min (24h/dia) } \\
\text { Resolução e extensão espacial: rede SIRGAS }\end{array}$ & $\begin{array}{c}\text { ftp.sirgas.org/pub/g } \\
\text { ps/SIRGAS-ZPD }\end{array}$ \\
\hline $\begin{array}{l}\mathrm{i} \\
\mathrm{c} \\
\mathrm{a}\end{array}$ & $\begin{array}{c}\text { EMBRACE/ZTD/IWV } \\
\text { GNSS }\end{array}$ & $\begin{array}{l}\text { VMF (elevação } 7^{\circ} \text { ) } \\
\text { Resolução e extensão temporal: } 5 \mathrm{~min}(24 \mathrm{~h} / \mathrm{dia}) \\
\text { Resolução e extensão espacial: rede RBMC }\end{array}$ & $\begin{array}{l}\text { http://www2.inpe.br } \\
\text { /climaespacial/porta } \\
\text { 1/iwv/ }\end{array}$ \\
\hline $\begin{array}{l}\text { d } \\
\text { o } \\
\text { S } \\
\text { u }\end{array}$ & $\begin{array}{c}\text { Atraso zenital CPTEC } \\
\text { PNT/CPTEC }\end{array}$ & $\begin{array}{c}d^{Z}, d_{h}^{Z}, d_{n h}^{Z} \\
\text { Resolução e extensão temporal: } 1 \mathrm{~h}(24 \mathrm{~h} / \mathrm{dia}) \\
\text { Resolução e extensão espacial: grade América do Sul }\end{array}$ & $\begin{array}{l}\text { http://satelite.cptec.i } \\
\text { npe.br/zenital/ }\end{array}$ \\
\hline $\begin{array}{l}1 \\
\mathrm{e} \\
\mathrm{B}\end{array}$ & $\begin{array}{c}\mathrm{BMF} \\
\text { Raytracer+PNT/CPTEC }\end{array}$ & $\begin{array}{c}\qquad d_{h}^{Z}, d_{n h}^{Z}, m f_{h}, m f_{n h} \\
\text { Resolução e extensão temporal: } 1 \mathrm{~h}(24 \mathrm{~h} / \mathrm{dia}) \\
\text { Resolução e extensão espacial: grade América do Sul }\end{array}$ & $\begin{array}{c}\text { Em } \\
\text { desenvolvimento }\end{array}$ \\
\hline $\begin{array}{l}\mathrm{a} \\
\mathrm{s} \\
\mathrm{i} \\
1\end{array}$ & $\begin{array}{l}\text { Atraso zenital automático } \\
\text { INMET/Un. Wyoming }\end{array}$ & $\begin{array}{l}d^{Z}, d_{h}^{Z}, d_{n h}^{Z} \\
\text { Resolução e extensão temporal: 6h ou 12h (24h/dia) } \\
\text { Resolução e extensão espacial: Brasil }\end{array}$ & $\begin{array}{c}\text { Em } \\
\text { desenvolvimento }\end{array}$ \\
\hline
\end{tabular}

Fonte: Os autores (2020).

\section{CONSIDERAÇÕES FINAIS E DESAFIOS FUTUROS}

O presente artigo discute em linhas gerais a sinergia entre a Meteorologia e a Geodésia. Por um lado, descreve a contribuição da Meteorologia na Geodésia, através da caracterização adequada da atmosfera visando à minimização dos efeitos da camada neutra na propagação dos sinais de radiofrequência. Por outro lado, descreve a contribuição da Geodésia na Meteorologia, na estimativa da concentração dos constituintes atmosféricos, como uma fonte adicional de informações. Nesse texto é feito um compêndio dos principais desenvolvimentos realizados nessa linha de pesquisa em ambas as vias, os quais não tem a pretensão de exaurir o assunto, mas dar um guia básico da trajetória da pesquisa realizada nos últimos 50 anos e uma indicação dos rumos futuros da pesquisa dentro da interação entre essas duas ciências. Outro ponto importante apresentado foram as discussões quanto a nomenclaturas: da camada livre de íons, neste artigo definida como atmosfera neutra, por ser a mais utilizada nas referências consolidadas e específicas da área, porém trazendo como sinônimo o termo neutrosfera (como apresentada por CHAPMAN (1950)); como das componentes da refratividade e do atraso, denominadas como hidrostática e não-hidrostática (ao invés de hidrostático e úmido), por serem os termos mais utilizados, ainda que nem sempre corretos.

No que tange à modelagem do atraso, nas últimas décadas os esforços foram direcionados para o posicionamento GNSS acurado. Sendo assim, modelos e fontes de dados foram sendo continuamente aprimorados. Além do atraso zenital, nos últimos anos também tem se investigado a modelagem e qualidade do atraso inclinado e das funções de mapeamento no território brasileiro (GOUVEIA, 2019) devido a sua complexidade climatológica. Os modelos empíricos globais (que utilizam a recuperação climatológica) são 
úteis para posicionamento não acurado, que pode ter erros de ordem métrica. Esses modelos não são capazes de expressar a variabilidade real do atraso, ao longo de um dia ou de horas, mas podem ser aplicados na ausência de outros modelos.

As demais fontes, isoladamente, como estações de superfície e as de altitude fornecem valores medidos dos constituintes atmosféricos, que aplicados aos modelos matemáticos (seção 3.2) fornecem medidas acuradas do atraso. Porém, essas medidas têm uma baixa resolução temporal, principalmente no território brasileiro. A sondagem atmosférica convencional, por meio de radiossondas acopladas a balões, medidas muitas vezes tomadas como referência do atraso, são técnicas de alto custo, o que restringe o número de lançamentos diários, apenas quatro por dia (6h UTC) (BEVIS et al., 1992). O atraso estimado no processamento das medidas GNSS é acurado (ROFATTO et al., 2012; ROFATTO, 2013; MARQUES, 2012), disponível 24 horas em todo o globo. Sua distribuição espacial se dará em consonância com os locais das estações GNSS. A rede global IGS (IGS, 2020) é composta por mais de 400 estações distribuídas em todo o mundo, 12 das quais estão localizadas no Brasil. A RBMC tem aproximadamente 150 estações operacionais (RBMC, 2020), 9 das quais pertencem também à IGS. Ou seja, no território nacional o atraso pode ser determinado em 153 estações, número que é muito maior do que nas décadas anteriores. Diante disso, os modelos de PNT se apresentam como boa alternativa quanto às limitações das outras estratégias na obtenção do atraso (SAPUCCI, 2001; CHEN et al., 2011), principalmente no Brasil. Uma desvantagem, que pode ser citada, é que as melhores representações da atmosfera, a análise (advinda da assimilação de dados), tem baixa resolução temporal e as demais medidas são obtidas por previsão. A eficiência da modelagem do atraso de propagação dependerá da qualidade das previsões do modelo de PNT. Modelos de PNT regionais, como os do CPTEC/INPE (CPTEC, 2020), têm alta resolução espacial, vertical e temporal, e podem ser considerados como melhores opções para o Brasil e América do Sul, uma vez que, a partir desses é possível obter a modelagem do atraso com valores mais próximos da realidade dessa região.

O monitoramento do vapor d'água atmosférico, que é o combustível para os eventos naturais atmosféricos mais catastróficos, é ainda uma questão em aberto, dada a deficiência das técnicas de observação da umidade presente na atmosfera. A ferramenta mais importante para a previsão de tempo é a modelagem numérica, mas para aplicações nowcasting ainda muito precisa ser melhorado para se ter resultados confiáveis e operacionalmente úteis na caracterização dos campos de umidade. Nesse contexto, os produtos GNSS para a meteorologia podem apresentar uma boa alternativa e merecem atenção. Os resultados reportados por Sapucci et al., (2019) evidenciam a existência de um padrão de comportamento nas variações do PWV GNSS em alta resolução temporal que antecede uma tempestade severa, o qual pode ser aprimorado visando aplicações nowcasting ainda não exploradas operacionalmente com o envolvimento das redes GNSS de monitoramento contínuo.

Portanto, fonte de dados que melhor representem as bruscas variações ocasionadas pelos eventos extremos e modelos que melhor proporcionam o cálculo do atraso, tanto zenital quanto inclinado, assim como a determinação das funções de mapeamento (por meio do traçado de raio), se apresentam como um grande desafio para a contribuição da Meteorologia para a Geodésia. Já na contribuição da Geodésia para a Meteorologia, pode haver uma forte aliança, buscando fornecer medidas cada vez mais acuradas de PWV (derivados do IWV acurado) e com maior resolução espacial, ou seja, a partir de um número ainda maior de estações GNSS terrestres. Também pode haver maior quantidade dos perfis de RO-GNSS, que são de suma importância na técnica de assimilação e consequentemente para os modelos de PNT. A tomografia do vapor d'água usando redes densas de receptores GNSS é uma outra fonte de informação para aplicações nowcasting, mas ainda não foi explorada no Brasil. Diante da climatologia brasileira tão peculiar, esses desafios apresentados se mostram ainda mais acentuados. Sendo assim, a sinergia entre Geodésia e Meteorologia, representa uma linha de pesquisas frutífera no passado e muito promissora para o futuro. 


\section{Agradecimentos}

Os autores agradecem a Coordenação de Aperfeiçoamento de Pessoal de Nível Superior (CAPES), ao Conselho Nacional de Desenvolvimento Científico e Tecnológico (CNPq) (processo 151351/2019-8).

\section{Contribuição dos Autores}

A autora TAFG foi responsável pela idealização e concepção do artigo. Os autores TAFG, LFS e FGN realizaram a conceptualização, redação inicial e revisão do artigo. Os autores DBMA e JFGM auxiliaram na conceptualização, revisão e supervisão do desenvolvimento do artigo.

\section{Conflitos de Interesse}

Os autores declaram que não há conflito de interesse.

\section{Referências}

ABREU, P. A. G. De; ALVES, D. B. M.; GOUVEIA, T. A. F. Aplicação e avaliação do modelo de previsão numérica do tempo eta15km no posicionamento absoluto. Revista Brasileira de Cartografia, [s. 1.], v. 66, n. 3, 2014.

ALVES, D. B. M.; DALBELO, L. F. A.; MONICO, J. F. G.; SAPUCCI, L. F. Modelagem Dinâmica do ZTD Versus Modelo de Hopfield: Resultados Obtidos Utilizando o Conceito de Estação Virtual. [s. 1.], n. Simpósio Brasileiro de Geofísica Espacial e Aeronomia-SBGEA, 2006.

ALVES, D. B. M.; MONICO, J. F. G.; DALBELO, L. F. A.; SAPUCCI, L. F.; CAMARGO, P. de O. VRS concept using NWP and Mod_Ion_FK: Preliminary Results in Brazil. In: XXIII INTERNATIONAL FIG CONGRESS: SHAPING THE CHANGE. Anais... . In: XXIII INTERNATIONAL FIG CONGRESS: SHAPING THE CHANGE. Munich, Germany, 2006.

ALVES, D. B. M.; MONICO, J. F. G.; DALBELO, L. F. A. Aplicando Diferentes Técnicas para Gerar Dados de Pseudodistância de uma Estação Virtual. XXIII Congresso Brasileiro de Cartografia. [s. 1.]. Anais... .XXIII Congresso Brasileiro de Cartografia, 2007.

ALVES, D.; DALBELO, L.; MONICO, G.; SAPUCCI, L. Evaluating the Performance of the CPTECINPE/FCT-UNESP Troposphere Dynamic Model Using the VRS Concept. AGU Spring Meeting Abstracts. [s. 1.], 2007.

ALVES, D. B. M.; SAPUCCI, L. F.; MARQUES, H. A.; DE SOUZA, E. M.; GOUVEIA, T. A. F; MAGÁRIO, J. A. Using a regional numerical weather prediction model for GNSS positioning over Brazil. GPS Solutions, [s. 1.], p. 677-685, 2015.

ASKNE, J.; NORDIUS, H. Estimation of tropospheric delay for microwaves from surface weather data. Radio Sci., 379-386, 1987.

Atmospheric Soundings. [s.d.]. Available in: <http://weather.uwyo.edu/upperair/sounding.html>. Acesso em: 31 jul. 2020.

BANOS, I. H. Assimilação em escala convectiva de dados de RO GNSS da constelação COSMIC-2: impactos na representação da atividade convectiva e ondas de gravidade sobre a Amazônia. 2017. Doutorado em Meteorologia - Instituto Nacional de Pesquisas Espaciais, São José dos Campos, 2017. Disponível em: http://mtc-m21b.sid.inpe.br/col/sid.inpe.br/mtcm21b/2017/02.03.10.32/doc/publicacao.pdf.

BANOS, I. H.; SAPUCCI, L. F.; CUCURULL, L.; BASTARZ, C. F.; SILVEIRA, B. B. Assimilation of GPSRO Bending Angle Profiles into the Brazilian Global Atmospheric Model. Remote Sens., 11, 256, 2019. 
BENDER, M.; STOSIUS, R.; ZUS, F.; DICK, G.; WICKERT, J.; RAABE, A. GNSS water vapour tomography - Expected improvements by combining GPS, GLONASS and Galileo observations. Advances in Space Research, Scientific applications of Galileo and other Global Navigation Satellite Systems - II. [s. 1.], v. 47, n. 5, p. 886-897, 2011.

BEVIS, M.; BUSINGER, S.; HERRING, T. A.; ROCKEN, C.; ANTHES, R. A.; WARE, R. H. GPS meteorology: Remote sensing of atmospheric water vapor using the global positioning system. Journal of Geophysical Research: Atmospheres, [s. 1.], v. 97, n. D14, p. 15787-15801, 1992.

BOEHM, J.; SCHUH, H. Vienna mapping functions in VLBI analyses. Geophysical Research Letters, [s. 1.], $\quad$ v. $\quad 31, \quad$ n. $\quad 1, \quad 2004 . \quad$ Disponível em: <https://agupubs.onlinelibrary.wiley.com/doi/abs/10.1029/2003GL018984>. Acesso em: 27 dez. 2020.

BOEHM, J.; NIELL, A.; TREGONING, P.; SCHUH, H. Global Mapping Function (GMF): A new empirical mapping function based on numerical weather model data. Geophysical Research Letters, [s. 1.], v. 33, n. 7, 2006a. Disponível em: <https://agupubs.onlinelibrary.wiley.com/doi/abs/10.1029/2005GL025546>. Acesso em: 27 dez. 2020.

BOEHM, J.; WERL, B.; SCHUH, H. Troposphere Mapping Functions for GPS and Very Long Baseline Interferometry from European Centre for Medium-Range Weather Forecasts Operational Analysis Data. Journal of Geophysical Research, [s. 1.], v. 111, 2006b.

BOEHM, J.; HEINKELMANN, R.; SCHUH, H. Short Note: A global model of pressure and temperature for geodetic applications. Journal of Geodesy, [s. 1.], v. 81, n. 10, p. 679-683, 2007.

BOHM, J.; SCHUH, H. (EDS.). Atmospheric Effects in Space Geodesy. Berlin Heidelberg: SpringerVerlag, 2013. Disponível em: <https://www.springer.com/gp/book/9783642369315>. Acesso em: 9 nov. 2020.

BOHM, J.; MOLLER, G.; SCHINDELEGGER, M.; PAIN, G.; WEBER, R. Development of an improved empirical model for slant delays in the troposphere (GPT2w). GPS Solutions, [s. 1.], v. 19, n. 3, p. 433441, 2015.

BONAFONI, S.; BIONDI, R.; BRENOT, H.; ANTHES, R. Radio occultation and ground-based GNSS products for observing, understanding and predicting extreme events: A review. Atmospheric research, [s. 1.], 2019. Disponível em: 〈https://agris.fao.org/agris-search/search.do?recordID=US201900336066>. Acesso em: 9 nov. 2020.

BRENOT, H.; ROHM, W.; KAČMAŘÍK, M.; MÖLLER, G.; SÁ, A.; TONDAŚ, D.; RAPANT, L.; BIONDI, R.; MANNING, T.; CHAMPOLLION, C. Cross-Comparison and Methodological Improvement in GPS Tomography. Remote Sensing, [s. 1.], v. 12, n. 1, p. 30, 2020.

CAMARGO, P. O. Modelo regional da ionosfera para uso em receptores de uma freqüência. 191pg. 1999. Doutorado em Ciências Geodésicas - Setor de Ciências da Terra, Universidade Federal do Paraná, Curitiba, 1999. Disponível em: <https://acervodigital.ufpr.br/bitstream/handle/1884/48840/T\%20\%20PAULO\%20DE\%20OLIVEIRA\%20CAMARGO.pdf?sequence=1\&isAllowed=y >

CAMPOS, T. L. O. B. O potencial de PWV-GPS em predizer tempestades: estudo de caso de linhas de instabilidade. 2018. Doutorado em Meteorologia - Instituto Nacional de Pesquisas Espaciais, São José dos Campos, 2018.

CANADA, E. Weather Information - Environment Canada. 2013. Available in: <https://weather.gc.ca/index_e.html>. Acesso em: 31 jul. 2020.

CDS. Climate Data Store. [s.d.]. Available in: <https://cds.climate.copernicus.eu/cdsapp\#!/home>. Acesso em: 28 dez. 2020.

CHAPMAN, S. Upper atmospheric nomenclature. Journal of Geophysical Research (1896-1977), [s. 1.], v. 55 , n. 4, p. 395-399, 1950.

CHEN, Q.; SONG, S.; HEISE, S.; LIOU, Y.-A.; ZHU, W.; ZHAO, J. Assessment of ZTD derived from ECMWF/NCEP data with GPS ZTD over China. GPS Solutions, [s. 1.], v. 15, n. 4, p. 415-425, 2011. 
COSMIC Home Page. [s.d.]. Disponível em: 〈https://www.cosmic.ucar.edu/〉. Acesso em: 9 nov. 2020.

CPTEC - Centro de Previsão de Tempo e Estudos Climáticos - INPE. [s.d.]. Disponível em: <https://www.cptec.inpe.br/>. Acesso em: 9 nov. 2020.

CPTEC/PNT. Centro de Previsão de Tempo e Estudos Climáticos - INPE - Previsão Numérica. [s.d.]. Disponível em: <https://previsaonumerica.cptec.inpe.br/bam>. Acesso em: 31 jul. 2020.

DALBELO, L. F. A; ALVES, D. B. M; MONICO, J. F. G.; SAPUCCI, L. F. Minimizando o atraso zenital troposférico no posicionamento DGPS: comparação da modelagem dinâmica com o modelo de Hopfield. Simpósio Brasileiro de Geofísica Espacial e Aeronomia - SBGEA. São José dos Campos - SP, 2006.

DAVIS, J. L.; HERRING, T. A.; SHAPIRO, I. I.; ROGERS, A. E. E.; ELGERED, G. Geodesy by radio interferometry: Effects of atmospheric modeling errors on estimates of baseline length. Radio Science, [s. 1.], v. 20, n. 6, p. 1593-1607, 1985.

ELGERED, G.; WICKERT, J. Monitoring of the Neutral Atmosphere. In: TEUNISSEN, P. J. G.; MONTENBRUCK, O. (Eds.). Springer Handbook of Global Navigation Satellite Systems. Springer HandbooksCham: Springer International Publishing, 2017. p. 1109-1138.

ESSEN e FROOME, 1951 apud TEUNISSEN, P. J. G.; MONTENBRUCK, O. (EDS.). Springer Handbook of Global Navigation Satellite Systems. [s.1.] : Springer International Publishing, 2017. Disponível em: <https://www.springer.com/gp/book/9783319429267>. Acesso em: 9 nov. 2020.

ECMWF | Public Datasets. [s.d.]. Disponível em: <https://apps.ecmwf.int/datasets/>. Acesso em: 31 jul. 2020.

FJELDBO, G.; ESHLEMAN, V. R. Atmosphere of Venus as studied with the Mariner 5 dual radio-frequency occultation experiment. Radio Science, [s. 1.], v. 4, n. 10, p. 879-897, 1969.

GUTMAN, S. I.; SAHM, S. R.; BENJAMIN, S. G.; SCHWARTZ, B. E.; HOLUB, K. L.; STEWART, J. Q.; SMITH, T. L. Rapid Retrieval and Assimilation of Ground Based GPS Precipitable Water Observations at the NOAA Forecast Systems Laboratory: Impact on Weather Forecasts. Journal of the Meteorological Society of Japan. Ser. II, [s. 1.], v. 82, n. 1B, p. 351-360, 2004.

GOUVEIA, T. A. F. Modelagem neutrosférica sobre a América do Sul baseada em PNT e assimilação de dados locais e robusta avaliação utilizando observações GNSS. 2013. Aleph, [s. 1.], p. 136 f.: il. Mestrado em Ciências Cartográficas - Universidade Estadual Paulista (UNESP), Presidente Prudente -SP, 2013. Disponível em: < https://repositorio.unesp.br/handle/11449/86823>.

GOUVEIA, T. A. F. Função de mapeamento brasileira da atmosfera neutra e sua aplicação no posicionamento GNSS na América do Sul. 2019. Doutorado em Ciências Cartográficas - Universidade Estadual Paulista (UNESP), Presidente Prudente - SP, 2019. Disponível em: <https://repositorio.unesp.br/handle/11449/186250>. Acesso em: 9 nov. 2020.

GOUVEIA, T. A. F.; SAPUCCI, L. F.; MONICO, J. F. G.; ALVES, D. B. M. Assessment of neutral atmospheric delay predictions based on the temporal resolution of an atmospheric model. Boletim de Ciências Geodésicas, v. 26, n. $\quad$ 1, 2020. Disponível em: $<$ http://www.scielo.br/scielo.php?script=sci_abstract\&pid=S1982-

21702020000100200\&lng=en\&nrm=iso\&tlng=en>. Acesso em: 2 set. 2020.

GONÇALVES, L. G. G. De. Uso da técnica de Relação de Newton para assimilação de dados de satélite em um modelo de área limitada. 1999. Revista Brasileira de Geofísica, 1999. Disponível em: <http://www.scielo.br/scielo.php?script=sci_abstract\&pid=S0102261X1999000200022\&lng=en\&nrm=iso\&tlng=pt>. Acesso em: 2 set. 2020.

GRUAN - GCOS Reference Upper-Air Network. [s.d.]. Disponível em: 〈https://www.gruan.org/>. Acesso em: 31 jul. 2020.

GUEROVA, G.; JONES, J.; DOUŠA, J.; DICK, G.; DE HAAN, S.; POTTIAUX, E.; BOCK, O.; PACIONE, R.; ELGERED, G.; VEDEL, H.; BENDER, M. Review of the state of the art and future prospects of the ground-based GNSS meteorology in Europe. Atmospheric Measurement Techniques, [s. 1.], v. 9, n. 11, 
p. 5385-5406, 2016.

HAJJ, G. A.; KURSINSKI, E. R.; ROMANS, L. J.; BERTIGER, W. I.; LEROY, S. S. A technical description of atmospheric sounding by GPS occultation. Journal of Atmospheric and Solar-Terrestrial Physics, [s. 1.], v. 64, n. 4, p. 451-469, 2002.

HECHT, E. Optics. 4th Edition, Addison-Wesley, p. 704, 2002.

HERRING, T. A. Modelling atmospheric delays in the analysis of space geodetic data. Proceedings of the Symposium Refraction of Transatmospheric Signals in Geodesy. eds. MUNCK, J. C. de, and SPOELSTRA, T. A. TH., No. 36, Netherlands Geodetic Commission, The Hague, The Netherlands, May 19-22, ISBN 9789061322436, pp. 157-164, 1992.

HOBIGER, T.; ICHIKAWA, R.; KOYAMA, Y.; KONDO, T. Fast and accurate ray-tracing algorithms for real-time space geodetic applications using numerical weather models. Journal of Geophysical Research: Atmospheres, [s. 1.], v. 113, n. D20, 2008. Disponível em: <https://agupubs.onlinelibrary.wiley.com/doi/abs/10.1029/2008JD010503>. Acesso em: 06 nov. 2020.

HOBIGER, T.; ICHIKAWA, R.; TAKASU, T.; KOYAMA, Y.; KONDO, T. Ray-traced troposphere slant delays for precise point positioning. Earth, Planets and Space, v. 60, n. 5, p. e1-e4, 2008.

HOFMANN-WELLENHOF, B.; LICHTENEGGER, H.; WASLE, E. GNSS - Global Navigation Satellite Systems: GPS, GLONASS, Galileo, and more. Wien: Springer-Verlag, 2008. Disponível em: <https://www.springer.com/gp/book/9783211730126>. Acesso em: 06 nov. 2020.

HOLZSCHUH, M. L. Recuperação de perfis atmosféricos a partir de ocultação GPS: fundamentos, implementação e análise de resultados. 2007. 127p. Mestrado em Ciências Cartográficas - Faculdade de Ciências e Tecnologia, Universidade Estadual Paulista, Presidente Prudente - SP, 2007.

HOPFIELD, H. S. Two-quartic tropospheric refractivity profile for correcting satellite data. Journal of Geophysical Research (1896-1977), [s. 1.], v. 74, n. 18, p. 4487-4499, 1969.

HOPFIELD, H. S. Tropospheric Effect on Electromagnetically Measured Range: Prediction from Surface Weather Data. Radio Science, [s. 1.], v. 6, n. 3, p. 357-367, 1971.

IFADIS, I. M. The atmospheric delay of radio waves: modeling the elevation dependence on a global scale. Licentiate thesis, Chalmers University of Technology, School of Electrical and Computer Engineering, Gothenburg, Sweden, 115 pp., Technical Report 38L, 1986.

INTERNATIONAL GNSS SERVICE (IGS). Enabling the highest-accuracy usability of openly available GNSS data \& products. [s.d.]. Disponível em: 〈https://www.igs.org/>. Acesso em: 31 de jul de 2020.

INTERNATIONAL EARTH ROTATION AND REFERENCE SYSTEMS SERVICE (IERS). About IERS. [s.d.]. Disponível em: <https://www.iers.org/IERS/EN/Organization/About/about.html;jsessionid=22C0B8B7499D9A6081C72 790E261DCAE.live1>. Acesso em: 31 de jul de 2020.

INMET. INSTITUTO NACIONAL DE METEOROLOGIA (INMET). 2020. Disponível em: <http://portal.inmet.gov.br/>. Acesso em: 31 de jul de 2020.

JEREZ, G. O. Recuperação e análise de perfis de densidade de elétrons para a região brasileira: aplicação de rádio ocultação integrada a dados de estações terrestres e mapas regionais ionosféricos. 2018. Doutorado em Ciências Cartográficas - Universidade Estadual Paulista, Presidente Prudente - SP. Em andamento.

KUO, Y.-H.; ZOU, X.; GUO, Y.-R. Variational Assimilation of Precipitable Water Using a Nonhydrostatic Mesoscale Adjoint Model. Part I: Moisture Retrieval and Sensitivity Experiments. Monthly Weather Review, [s. 1.], v. 124, n. 1, p. 122-147, 1996.

KURSINSKI, E. R.; HAJJ, G. A.; LEROY, S. S.; HERMAN, B. The GPS Radio Occultation Technique. In: LEE, L.C.; ROCKEN, C.; KURSINSKI, R. Applications of Constellation: Observing System for Meteorology, Ionosphere e Climate. Hong Kong: Springer-Verlag, 2000.

LAGLER, K.; SCHINDELEGGER, M.; BÖHM, J.; KRÁSNÁ, H.; NILSSON, T. GPT2: Empirical slant delay 
model for radio space geodetic techniques. Geophysical Research Letters, [s. 1.], v. 40, n. 6, p. 10691073, 2013.

LANDSKRON, D.; BÖHM, J. VMF3/GPT3: refined discrete and empirical troposphere mapping functions. Journal of Geodesy, [s. 1.], v. 92, n. 4, p. 349-360, 2018.

LEANDRO, R.; SANTOS, M.; LANGLEY, R. UNB Neutral Atmosphere Models: Development and Performance. In: 2006, Anais... . In: PROCEEDINGS OF THE 2006 NATIONAL TECHNICAL MEETING OF THE INSTITUTE OF NAVIGATION. [s.l: s.n.]. Disponível em: <http://www.ion.org/publications/abstract.cfm?.jp=p\&articleID=6562>. Acesso em: 31 jul. 2020.

LIMA, T. M. A.; ALVES, D. B. M.; GOUVEIA, T. A. F. Estudo do comportamento do atraso troposférico a partir de diferentes modelos. In: Simpósio SIRGAS 2019, 2019, Rio de Janeiro. Anais... . Simpósio SIRGAS 2019, 2019.

MACDONALD, A. E.; MACDONALD, A. E. On the use of slant observations from GPS to diagnose three dimensional water vapor using 3DVAR. In: 2000, Anais... In: 80TH AMS ANNUAL MEETING. : AMS, 2000. Disponível em: <https://ams.confex.com/ams/annual2000/webprogram/Paper11437.html>. Acesso em: 31 jul. 2020.

MARINI, J. W. Correction of satellite tracking data for an arbitrary tropospheric profile. Radio Science, [s. 1.], v. 7, n. 2, p. 223-231, 1972.

MARQUES, H. A.; MONICO, J. F. G.; AQUINO, M. RINEX_HO: second- and third-order ionospheric corrections for RINEX observation files. GPS Solutions, [s. 1.], v. 15, n. 3, p. 305-314, 2011.

MARQUES, H. A. PPP em tempo real com estimativa das correções dos relógios dos satélites no contexto de rede GNSS. 2012. Doutorado em Ciências Cartográficas. Universidade Estadual Paulista (UNESP), Presidente Prudente. São Paulo, 2012. Disponível em: <https://repositorio.unesp.br/handle/11449/100256>. Acesso em: 31 jul. 2020.

MARQUES, H. A.; MONICO, J. F. G.; MARQUES, H. A. S.; AQUINO, M. Análise dos efeitos ionosféricos de ordem superior no ciclo solar 24 e influência no posicionamento GNSS absoluto. Boletim de Ciências Geodésicas, [s. 1.], v. 20, n. 4, 2014. Disponível em: 〈https://revistas.ufpr.br/bcg/article/view/38956>. Acesso em: 31 jul. 2020.

MENDES, V. D. B. Modeling the Neutral-Atmosphere Propagation Delay in Radiometric Space Techniques. 1999. Ph.D Thesis. Dept. of Geodesy and Geomatics Engineering, Fredericton, N.B., Canada, 353 pages 1999. Disponível em: <http://adsabs.harvard.edu/abs/1998PhDT........14M>. Acesso em: 31 jul. 2020.

MOELlER, G.; AO, C.; ADAVI, Z.; BRENOT, H.; SÁ, A.; HAJJ, G.; HANNA, N.; KITPRACHA, C.; POTTIAUX, E.; ROHM, W.; SHEHAJ, E.; TRZCINA, E.; WANG, K.-N.; WILGAN, K.; ZHANG, K. Sensing small-scale structures in the troposphere with tomographic principles (IAG working group). In: EGU2020. Copernicus Meetings, 2020. Disponível em: <https://meetingorganizer.copernicus.org/EGU2020/EGU2020-8469.html>. Acesso em: 9 nov. 2020.

MONICO, J. F. G. GNSS: investigações e aplicações no posicionamento geodésico, em estudos relacionados com a atmosfera e na agricultura de precisão. Projeto FAPESP na modalidade temático. Universidade Estadual Paulista. Presidente Prudente, SP, 2006. Disponível em: $<$ https://bv.fapesp.br/pt/auxilios/2147/gnss-investigacoes-e-aplicacoes-no-posicionamento-geodesicoem-estudos-relacionados-com-a-atmosfer/>. Acesso em: 31 jul. 2020.

MONICO, J. F. G. Posicionamento pelo GNSS: Descrição, Fundamentos e Aplicações. $2^{\text {a }}$ edição ed. São Paulo: Editora Unesp, 2008.

MONICO, J. F. G.; POZ, A. P. D.; GALO, M.; SANTOS, M. C. D.; OLIVEIRA, L. C. D. Acurácia e precisão: revendo os conceitos de forma acurada. Boletim de Ciências Geodésicas, v. 15, n. 3, 2009. Disponível em: <https://revistas.ufpr.br/bcg/article/view/15513>. Acesso em: 31 jul. 2020.

MORAES, V. V. S. Análise do Comportamento de Perfis Atmosféricos a Partir de Dados de RO GNSS para a Região Brasileira. 2020. Mestrado em Ciências Cartográficas - FCT/UNESP. Em andamento. 
NAFISI, V.; URQUHART, L.; SANTOS, M. C.; NIEVINSKI, F. G.; BOHM, J.; WIJAYA, D. D.; SCHUH, H.; ARDALAN, A. A.; HOBIGER, T.; ICHIKAWA, R.; ZUS, F.; WICKERT, J.; GEGOUT, P. Comparison of Ray-Tracing Packages for Troposphere Delays. IEEE Transactions on Geoscience and Remote Sensing, [s. 1.], v. 50, n. 2, p. 469-481, 2012.

NIELL, A. E. Global mapping functions for the atmosphere delay at radio wavelengths. Journal of Geophysical Research: Solid Earth, [s. 1.], v. 101, n. B2, p. 3227-3246, 1996.

NIELL, A. E. Improved atmospheric mapping functions for VLBI and GPS. Earth, Planets and Space, v. 52, n. 10, p. 699-702, 2000.

NIELL, A. E. Preliminary evaluation of atmospheric mapping functions based on numerical weather models. Physics and Chemistry of the Earth, Part A: Solid Earth and Geodesy, Proceedings of the First COST Action 716 Workshop Towards Operational GPS Meteorology and the Second Network Workshop of the International GPS Service (IGS). [s. 1.], v. 26, n. 6, p. 475-480, 2001.

NIEVINSKI, F. G. Ray-tracing options to mitigate the neutral atmosphere delay in GPS. 2009. Master of Science in Engineering - Dept. of Geodesy and Geomatics Engineering, Fredericton, N.B., Canada, 230 pages, 2009. Disponível em: < http://www2.unb.ca/gge/Pubs/TR262.pdf>. Acesso em: 31 jul. 2020.

NIEVINSKI, F. G.; SANTOS, M. C. Ray-tracing options to mitigate the neutral atmosphere delay in GPS. Geomatica, [s. 1.], v. 64, p. 191-207, 2010.

OLIVEIRA, A. da F. De. Análise comparativa de diferentes modelos troposféricos para RTK em rede usando o conceito de estação de referência virtual. 2013. Mestrado em Ciências Geodésicas - Setor de Ciencias da Terra. Universidade Federal do Paraná, Curitiba. Paraná, 177p, 2013. Disponível em: <https://acervodigital.ufpr.br/handle/1884/31786>. Acesso em: 31 jul. 2020.

OLIVEIRA, A. D. F. D.; ALVES, D. B. M.; FERREIRA, L. D. D. Análise de modelos troposféricos no posicionamento baseado em redes usando o conceito de VRS. Boletim de Ciências Geodésicas, [s. 1.], v. 20, n. 1, p. 39-53, 2014a.

OliveIRA, A. da F. De; ALVES, D. B. M.; FERREIRA, L. D. D. Avaliação de diferentes modelos troposféricos de previsão numérica de tempo no posicionamento em redes. Revista Brasileira de Cartografia, [s. 1.], v. 66, n. 3, 2014b. Disponível em: <http://www.seer.ufu.br/index.php/revistabrasileiracartografia/article/view/44765>. Acesso em: 31 jul. 2020.

RBMC. Rede Brasileira de Monitoramento Contínuo dos Sistemas GNSS | IBGE. Disponível em: $<$ https://www.ibge.gov.br/geociencias/informacoes-sobre-posicionamento-geodesico/redegeodesica/16258-rede-brasileira-de-monitoramento-continuo-dos-sistemas-gnss-rbmc.html>. Acesso em: 31 jul. 2020.

GNSS-SP. Rede GNSS Ativa do Estado de São Paulo. Disponível em: <https://www.fct.unesp.br/\#!/pesquisa/grupos-de-estudo-e-pesquisa/gege/rede-gnss-sp2089/>. Acesso em: 31 de jul. de 2020.

ROHM, W.; YUAN, Y.; BIADEGLGNE, B.; ZHANG, K.; MARSHALL, J. L. Ground-based GNSS ZTD/IWV estimation system for numerical weather prediction in challenging weather conditions. Atmospheric Research, v. 138, p. 414-426, 2014.

ROFATTO, V.; MONICO, G.; SAPUCCI, L. Estimativa do vapor d'água integrado utilizando dados de estações GNSS terrestres e estações meteorológicas: aplicações nowcasting. In: ANAIS DO III SBG SIMPÓSIO BRASILEIRO DE GEOMÁTICA, 2012. Anais... . In: III SBG - SIMPÓSIO BRASILEIRO DE GEOMÁTICA. Presidente Prudente-SP, Brasil, 2012.

ROFATTO, V. F. ZTD em tempo quase real via Estações GNSS Terrestres: estratégia de processamento para o GIPSY-OASIS II e combinação das séries temporais. 2013. 125f. Mestrado em Ciências Cartográficas. Universidade Estadual Paulista (UNESP), Presidente Prudente - SP, 2013. Disponível em: <https://repositorio.unesp.br/handle/11449/113819>. Acesso em: 31 jul. 2020.

SAASTAMOINEN, J. Atmospheric Correction for the Troposphere and Stratosphere in Radio Ranging 
Satellites. In: The Use of Artificial Satellites for Geodesy. American Geophysical Union (AGU), p. 247-251, 1972.

SAPUCCI, L. F. Estimativa do vapor d'água atmosférico e avaliação da modelagem do atraso zenital troposférico utilizando GPS. 2001. Mestrado em Ciências Cartográficas. Universidade Estadual Paulista, Faculdade de Ciências e Tecnologia, Presidente Prudente - SP, Brasil, 2001. Disponível em: <https://repositorio.unesp.br/handle/11449/88549>. Acesso em: 31 jul. 2020.

SAPUCCI, L. F. Estimativas do IWV utilizando receptores GPS em bases terrestres no Brasil: sinergia entre a geodésia e a meteorologia. 2005. Doutorado em Ciências Cartográfica. Universidade Estadual Paulista (UNESP), Presidente Prudente - SP, 2005. Disponível em: <https://repositorio.unesp.br/handle/11449/100933>. Acesso em: 31 jul. 2020.

SAPUCCI, L. F.; MACHADO, L. A. T.; MONICO, J. F. G. Previsões do atraso zenital troposférico para a América do Sul: variabilidade sazonal e avaliação da qualidade. Revista Brasileira de Cartografia, [s. 1.], $\quad$ v. $\quad 58, \quad$ n. $\quad 3, \quad 2006 . \quad$ Disponível <http://www.seer.ufu.br/index.php/revistabrasileiracartografia/article/view/44913>. Acesso em: 31 jul. 2020.

SAPUCCI, L. F.; MACHADO, L. A. T.; MONICO, J. F. G.; PLANA-FATTORI, A. Intercomparison of integrated water vapor estimates from multisensors in the amazonian region. Journal of Atmospheric and Oceanic Technology, [s. 1.], p. 1880, 2007a.

SAPUCCI, L. F.; MONICO, J. F. G.; MACHADO, L. A. T.; HERDIES, D. L.; SOUZA, R. A. F. De. Assimilação do IWV-GPS no Brasil: otimização das estimativas do atraso zenital troposférico em tempo real. Revista Brasileira de Geofísica, [s. 1.], v. 25, n. 3, p. 267-279, 2007b.

SAPUCCI, L. F.; MONICO, J. F. G.; ADAMS, D. K.; ROSA, G. P. S.; SCHUBERT, D. V.; VITORELO, I. Evolução do GNSS Meteorologia no Brasil Beneficiando a Previsão Numérica de Tempo sobre a América do Sul. In: CONGRESSO BRASILEIRO DE METEOROLOGIA. Belém - PA, Anais... . 2010.

SAPUCCI, L. F. Evaluation of Modeling Water-Vapor-Weighted Mean Tropospheric Temperature for GNSSIntegrated Water Vapor Estimates in Brazil. Journal of Applied Meteorology and Climatology, [s. 1.], v. 53, n. 3, p. 715-730, 2014a.

SAPUCCI, L. F.; BASTARZ, C. F.; CERQUEIRA, F.; AVANÇO, L. A.; HERDIES, D. L. Impacto de perfis de rádio ocultação GNSS na qualidade das Previsões de tempo do CPTEC/INPE. Revista Brasileira de Meteorologia, [s. 1.], v. 29, n. 4, p. 551-567, 2014b.

SAPUCCI, L. F.; MACHADO, L. A. T.; SOUZA, E. M. De; CAMPOS, T. B. Global Positioning System precipitable water vapour (GPS-PWV) jumps before intense rain events: A potential application to nowcasting. Meteorological Applications, [s. 1.], v. 26, n. 1, p. 49-63, 2019.

SEEBER, G. Satellite Geodesy: Foundations, Methods, and Applications. 2nd completely revised and extended edition. Walter de Gruyter. Berlin, New York, 2003. Disponível em: <https://www.degruyter.com/view/title/12128>. Acesso em: 31 jul. 2020.

SETTI JR, P. de T.; ALVES, D. B. M.; GOUVEIA, T. A. F. Uso integrado dos sistemas Galileo e GPS: uma análise da acurácia no posicionamento por ponto com correções atmosféricas. Revista Brasileira de Cartografia, [s. 1.], v. 68, n. 3, p. 595-607, 2016.

SILVA, N. C. C. Da; SANTOS, M. C. Dos; OLIVEIRA, L. C. De. Efeito da refração troposférica no posicionamento geodésico com GPS. Revista Brasileira de Geofísica, [s. 1.], v. 17, n. 2-3, p. 117-128, 1999.

SMART, W. M. Spherical Astronomy. 6a edição ed. Cambridge; New York: Cambridge University Press, 1977.

SMITH, T. L.; BENJAMIN, S. G.; GUTMAN, S. I.; SAHM, S. Short-Range Forecast Impact from Assimilation of GPS-IPW Observations into the Rapid Update Cycle. Monthly Weather Review, [s. 1.], v. 135, n. 8, p. 2914-2930, 2007. 
SPILKER, J., J. JR. Tropospheric Effects on GPS. Global Positioning System: Theory and Applications, American Institute of Aeronautics and Astronautics. Vol 1 Cap. 13, pg. 517 - 546, 1994.

TEUNISSEN, P. J. G; MONTENBRUCK, O. Springer Handbook of Global Navigation Satellite Systems. Springer Handbooks, 2017. DOI.: 10.1007/978-3-319-42928-1.

THAYER, G. D. An improved equation for the radio refractive index of air. Radio Science, [s. 1.], v. 9, n. 10, p. 803-807, 1974.

TRALLI, D. M.; LICHTEN, S. M. Stochastic estimation of tropospheric path delays in global positioning system geodetic measurements. Bulletin géodésique, [s. 1.], v. 64, n. 2, p. 127-159, 1990.

URQUHART, L. Assessment of Tropospheric Slant Factor Models: Comparison with Three Dimensional Ray-Tracing and Impact on Geodetic Positioning. 2010. Masters of Science in Engineering - University of New Brunswick, Department of Geodesy and Geomatics Engineering, Fredericton, NB, Canada, 2010. Disponível em: <https://www.researchgate.net/publication/50244872_Assessment_of_Tropospheric_Slant_Factor_Mode 1s_Comparison_with_Three_Dimensional_Ray-Tracing_and_Impact_on_Geodetic_Positioning >

URQUHART L, SANTOS MC. Development of a VMF1-like service at UNB. Retrieved from http://unbvmf1.gge.unb.ca/publications/VMF1-UNB_White_paper.pdf. 8, 2011.

VENDRASCO, E. P.; SAPUCCI, L. F.; KHAMIS, E. G.; MATTOS, J. G. Z.; AVANÇO, L. A.; BAÑOS, I. H.; CAMPOS, T. L. O. B.; GONÇALVES, L. G. G. Sistema de modelagem regional (SMR) versão 2.0 (Olímpica). Relatório Técnico, INPE, São José dos Campos, 2016.

VIANELLO, R. L.; ALVES, A. R. Meteorologia básica e aplicações. Universidade Federal de Viçosa (UFV), Viçosa: Editora UFV, 448 p., 2000.

VMF Codes. Index of codes. [s.d.]. Disponível em: <https://vmf.geo.tuwien.ac.at/codes/>. Acesso em: 31 jul. 2020.

WALLACE JOHN M, HOBBS P. V. Atmospheric Science: An introductory survey. University of Washington, 2nd ed, 2005.

Weather|NOAA - National Oceanic and Atmospheric Administration. [s.d.]. Disponível em: <https://www.noaa.gov/weather>. Acesso em: 31 jul. 2020.

YAN, X.; DUCROCQ, V.; JAUBERT, G.; BROUSSEAU, P.; POLI, P.; CHAMPOLLION, C.; FLAMANT, C.; BONIFACE, K. The benefit of GPS zenith delay assimilation to high-resolution quantitative precipitation forecasts: a case-study from COPS IOP 9. Quarterly Journal of the Royal Meteorological Society, [s. 1.], v. 135, n. 644, p. 1788-1800, 2009.

ZHANG, W.; ZHANG, S.; DING, N.; ZHAO, Q. A Tropospheric Tomography Method with a Novel Height Factor Model Including Two Parts: Isotropic and Anisotropic Height Factors. Remote Sensing, [s. 1.], v. 12, n. 11, p. 1848, 2020.

\section{Biografias dos autores}

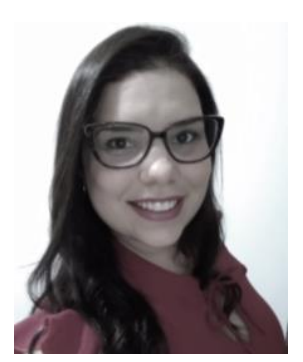

Tayná Aparecida Ferreira Gouveia nasceu na cidade de Santos - SP no ano de 1985. Possui graduação em Licenciatura em Matemática pela Universidade Estadual Paulista (UNESP), Faculdade de Ciência e Tecnologia (FCT) em 2008; mestrado em 2013; doutorado em 2019. Atualmente Pós-Doutorado (2019-) em Ciências Cartográficas na referida instituição. Têm experiência na área de Geodésia Celeste, Global Navigation Satellite Systems (GNSS) para o monitoramento da atmosfera neutra, com ênfase na sinergia entre Geodésia e Meteorologia. Atua principalmente na modelagem da atmosfera neutra (troposfera), visando a melhoria na qualidade do posicionamento GNSS. 

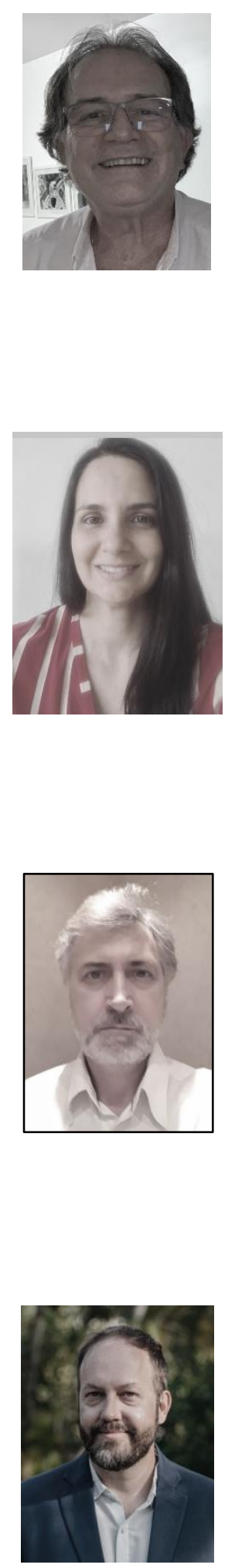

João Francisco Galera Monico, nasceu em Lupionópolis, PR em 1956. Possui graduação em Engenharia Cartográfica pela Unesp (1982), Mestrado em Ciências Geodésicas pela UFPR (1988) e Doutorado em Geodésia Espacial pela Univeristy Of Nottinhgam (1995). Possui experiência na área de Geodésia, principalmente em Geodésia Celeste, GNSS para Geodésia e Monitoramento da Atmosfera, Ajustamento de Observações e Controle de Qualidade em Geodésia. É autor do livro Posicionamento pelo GNSS e vários artigos. Coordenou e coordena vários projetos financiados pelas principais agências de fomentos do Brasil, em destaque o INCT GNSS NavAer. Atualmente é Pesquisador II na Unesp, em Presidente Prudente.

Daniele Barroca Marra Alves nasceu na cidade de Presidente Prudente - SP no ano de 1980. É professora Assistente Doutora do Departamento de Cartografia da Universidade Estadual Paulista - UNESP e membro do Programa de PósGraduação em Ciências Cartográficas. Possui graduação em Matemática pela FCT - UNESP (2001). Finalizou o Mestrado em Ciências Cartográficas em 2004, o Doutorado em 2008 e o Pós-Doutorado em 2011, na mesma instituição. Desde 2012 é pesquisadora do Conselho Nacional de Desenvolvimento Científico e Tecnológico $(\mathrm{CNPq})$. Suas principais áreas de atuação são a modelagem atmosférica, rádio ocultação e o posicionamento GNSS (Global Navigation Satellite System).

Luiz Fernando Sapucci é matemático mestre e doutor em Ciências Cartográficas UNESP de Pres. Prudente, 2001 e 2005, respectivamente, com Pós Doutorado em Assimilação de dados atmosféricos no Programa de Pós graduação em Meteorologia do INPE em 2014. Atualmente é pesquisador do INPE atuando como coordenador das atividades sobre assimilação de dados na Divisão de Modelagem Numérica do Sistema Terrestre (DIMNT) da Coordenação Geral do Sistema Terrestre (CGCT-CPTEC-INPE). Sua especialidade é aplicações GNSS em atividades ligadas a Meteorologia, em especial na assimilação de dados e no desenvolvimento de ferramentas de curtíssimo prazo para eventos intensos de precipitação.

Felipe Geremia-Nievinski completou a graduação em Engenharia Cartográfica (EG) pela UFRGS em 2005; o Mestrado em Engenharia Geomática pela UNB em Fredericton, Canadá em 2009; e o PhD em Engenharia Aeroespacial pela Universidade do Colorado EUA em 2013. Em 2016 ele se tornou professor na UFRGS (Departamento de Geodésia), onde também atua como coordenador do curso de graduação em EG e como orientador no PPG em Sensoriamento Remoto. Seus interesses de pesquisa incluem geodésia por satélite, com foco na refração atmosférica, bem como Refletometria GPS/GNSS. Ele é membro da Associação Internacional da Geodésia e editor associado do Journal of Geodesy. 